\title{
Interdisciplinaridade e Teoria de Redes: rede semântica de cliques baseada em ementas e rede de componentes curriculares
}

\section{Title: Interdisciplinarity and Network Theory: semantic networks of cliques based on course descriptions and network of courses}

\author{
Júlia Carvalho Andrade1, Renata Souza Freitas Dantas Barreto², Marcelo do Vale \\ Cunha $^{2}$, Núbia Moura Ribeiro ${ }^{1}$, Hernane Borges de Barros Pereira ${ }^{1,2}$ \\ ${ }^{1}$ Doutorado Multi-Institucional e Multidisciplinar em Difusão do Conhecimento - \\ Universidade Federal da Bahia (UFBA) - Salvador - BA - Brasil \\ ${ }^{2}$ Programa de Modelagem Computacional - SENAI-CIMATEC - \\ Salvador - BA - Brasil \\ juliacarvalhoandrade@yahoo.com.br, \{renatasouzabarreto, celaocunha, \\ nubiamouraribeiro, hernanebbpereira\}@gmail.com
}

\begin{abstract}
.
This work proposes to investigate the semantic networks of cliques based on the syllabus of a doctoral postgraduate program. A total of 46 course descriptions were compiled. Using appropriate indices of social and complex networks as a starting point, we conclude that degree, closeness and betweenness are adequate pointers to the coherence and consistency among the doctoral postgraduate program objectives and its set of course descriptions. Also, the identification of common subject topics that occur in different course descriptions highlights the interactions that may exist between the different disciplines on offer .
\end{abstract}

Keywords. Networks theory; Curriculum; Subjects; Doctoral postgraduate program.

Resumo. Este trabalho propõe investigar a rede semântica de cliques baseada em ementas de um programa de pós-graduação de doutorado. Foram coletadas 46 ementas de componentes curriculares. Usando alguns índices de redes sociais e complexas como ponto de partida, observou-se que as centralidades de grau, proximidade e intermediação são índices adequados para perceber a coerência e consistência da proposta de um programa com seu ementário. E a identificação dos temas em comum às ementas auxilia na percepção das interações entre os componentes curriculares de um programa.

Palavras-Chave. Teoria de redes; Currículo; Disciplinas; Programas de pós-graduação.

Cite as: Andrade, J. C., Barreto, R. S. F. D., Cunha, M. V., Ribeiro, N. M \& Pereira, H. B. B. (2019). Interdisciplinarity and Network Theory: semantic networks of cliques based on course descriptions and network of courses (Interdisciplinaridade e Teoria de Redes: rede semântica de cliques baseada em ementas e rede de componentes curriculares). iSys: Revista Brasileira de Sistemas de Informação (Brazilian Journal of Information Systems), 12(3), 24-52. 


\section{Introdução}

Os componentes curriculares que compõem a matriz curricular de um programa de pósgraduação (PPG) têm como objetivo proporcionar os conhecimentos necessários ao aprendizado proposto pelo PPG. Cada componente curricular possui uma ementa que consiste em uma descrição discursiva e resumida do seu conteúdo teórico (conceitual) ou teórico-metodológico (conceitual/procedimental). Nesse sentido, o ementário de um PPG pode ser considerado um discurso escrito, o qual deve refletir sua proposta de aprendizado. Ademais, cada ementa pode ser considerada uma sentença do discurso e o universo de palavras das ementas representa o vocabulário do discurso do PPG.

No Brasil, os programas de pós-graduação são avaliados e reconhecidos pela Coordenação de Aperfeiçoamento de Pessoal de Nível Superior (CAPES), e classificados em áreas de concentração, dentro de áreas de avaliação. Segundo a CAPES (2013), a matriz curricular de um PPG deve ser adequada à formação de mestres e doutores, e constituída por um conjunto de componentes curriculares congruente com suas áreas de concentração e linhas de pesquisa. Desta forma, os textos descritivos das áreas de concentração e linhas de pesquisa de um PPG devem refletir sua proposta de aprendizado e espera-se coerência e consistência com seu ementário.

Além disso, espera-se que haja organicidade entre todos os elementos que constituem um PPG: proposta do programa, áreas de concentração, linhas de pesquisa, matriz curricular, corpo docente e discente, estrutura física, meio social, produções intelectuais, entre outros. O sistema CAPES de avaliação da pós-graduação brasileira avalia a coerência e consistência entre esses elementos por meio de critérios de avaliação. A falta de coerência e consistência entre esses elementos está entre as principais causas de reprovação de programas de pós-graduação interdisciplinares pela CAPES, e, por esse motivo, deve ser investigada.

Parece razoável afirmar que diversos sistemas naturais e sociais contêm elementos que se relacionam entre si, e um PPG pode ser considerado um deles, principalmente quando se trata de programas da área interdisciplinar. Esses sistemas são chamados de sistemas complexos quando possuem diversos elementos que interagem entre si no tempo e no espaço e destas interações emergem propriedades que vão além da soma das partes que constituem o sistema como um todo. Outra característica desses sistemas é que são bastante sensíveis às condições iniciais [Nussensveig 2008]. Redes complexas consistem em um tipo de sistema complexo, cujos elementos constituintes são vértices e arestas ou arcos que estabelecem as relações entre os vértices.

Assim, para avaliar a coerência e a consistência entre a proposta de aprendizado baseada nas áreas de concentração e nas linhas de pesquisa de um PPG e o ementário relativo à sua matriz curricular, o objetivo deste trabalho é apresentar um modelo de análise de ementário e de componentes curriculares de um PPG em nível de doutorado, por meio de uma rede semântica de cliques baseada em ementas (rede de ementas), de uma rede de componentes curriculares, e do uso de temas-chave (i.e. conceitos representativos da proposta de aprendizado do PPG investigado extraídos dos textos descritivos das áreas de concentração e títulos das linhas de pesquisa).

Reiterando o que foi dito anteriormente, na avaliação de um PPG pela CAPES (2013) é observada "coerência, consistência, abrangência e atualização das áreas de concentração, linhas de pesquisa, projetos em andamento e proposta curricular". No 
documento da área de avaliação interdisciplinar (CAPES, 2013), de onde essa informação foi retirada, a CAPES não explicita o que entende por coerência e consistência. Neste trabalho, entende-se por coerência a conexão ou ligação entre as ideias principais das áreas de concentração, linhas de pesquisa, projetos em andamento e a matriz curricular. E consistência significa a coesão ou compatibilidade entre estas ideias, ou seja, a não contradição das ideias. Considerando que essas ideias são representadas pelos temaschave supracitados, se os vértices que consistem nos temas-chave tiverem grande importância de grau, intermediação e proximidade em uma rede de ementas, pode-se inferir que existe coerência e consistência entre as áreas de concentração, linhas de pesquisa e matriz curricular do PPG investigado. Ademais, índices da teoria das redes complexas, como caminho mínimo médio e coeficiente de aglomeração médio, também demostram a coerência e consistência entre as ementas, conforme será discutido mais adiante. Assim, a coerência e a consistência entre as áreas de concentração, linhas de pesquisa e a matriz curricular, essa última representada pelas ementas dos componentes curriculares, serão investigadas por meio de índices da análise de redes sociais e índices da teoria das redes complexas em uma rede de ementas.

E para modelar as conexões entre os componentes curriculares, foi proposto um método de criação e análise de rede de componentes curriculares que represente as conexões entre eles por meio de temas-chave em comum. A fragmentação do conhecimento em componentes curriculares (i.e. disciplinas obrigatórias, disciplinas optativas ou atividades) dificulta a visualização das interações entre eles, dando a falsa ideia de que são isolados. Modelar as conexões entre os componentes curriculares é uma forma de representação e percepção da multi/interdisciplinaridade de um curso. Isto auxilia a visualização e implementação de abordagens multi/interdisciplinares na prática dos currículos, oportunizando a colaboração entre os componentes curriculares, discentes, docentes e grupos de pesquisa.

Vale salientar que redes semânticas de cliques baseadas em ementas e redes de componentes curriculares ainda não foram descritas na literatura científica até o presente momento.

\section{Fundamentação teórica}

\subsection{Conceitos fundamentais}

Uma rede semântica é um sistema de representação do conhecimento estabelecido pelo contexto e imbuído de intenção de funcionalidade. Uma rede semântica é composta de palavras, conceitos ou entidades com significado semântico, representados pelos vértices. $\mathrm{E}$ as arestas ou arcos consistem em conexões entre as palavras que aparecem na mesma unidade de significado, i.e. em uma sentença (frase), um parágrafo ou um título do discurso analisado. As redes semânticas são representadas por grafos [Pereira et al. 2016; Grilo et al. 2017].

As redes semânticas de cliques consistem em um tipo de rede semântica em que todas as palavras de cada sentença do discurso (e.g. texto) se conectam formando um subgrafo, chamado de clique. Assim, uma clique é um subgrafo completo de um grafo $G$. E as cliques se conectam formando a rede semântica do discurso [Fadigas e Pereira 2013]. Na Figura 1, são apresentados o estado inicial de cliques isoladas (Figura 1a) e uma possível rede de cliques (Figura 1b). 
As redes de cliques são formadas por justaposição e/ou sobreposição de cliques. $\mathrm{O}$ processo de justaposição significa conectar duas cliques com apenas um vértice em comum (e.g. os vértices 0,3 , 4, e 5 apresentados na Figura 1b). E quando dois ou mais vértices conectam as cliques ocorre o processo de sobreposição (e.g. os vértices 1, 2, 6, 7, 8 e 9 apresentados na Figura 1b) [Fadigas e Pereira 2013].

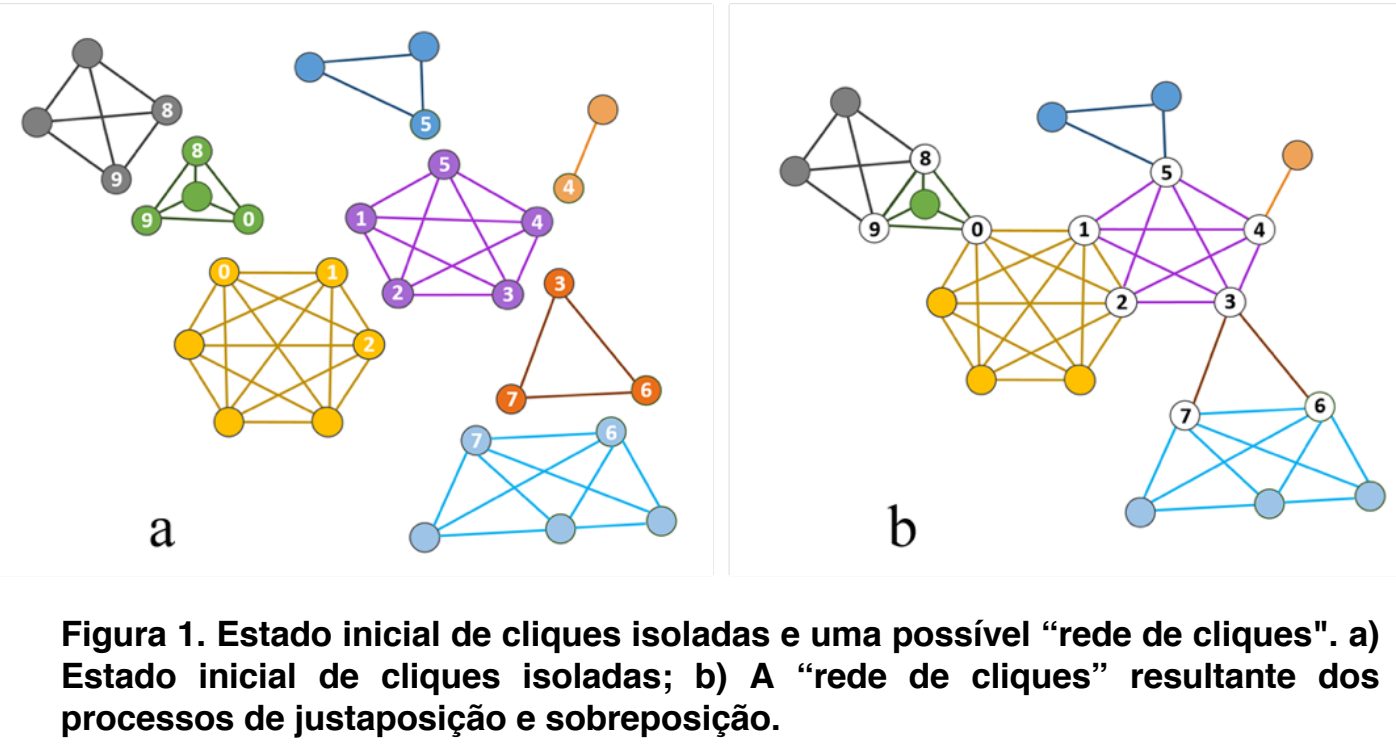

\subsection{Trabalhos correlatos}

Diversos trabalhos investigaram discursos por meio de redes de cliques. Por exemplo, Caldeira et al. (2006) utilizaram redes de palavras baseadas em cliques para analisar a estrutura de conceitos significativos em textos escritos. Redes semânticas baseadas em títulos de artigos de periódicos científicos (RST) foram estudadas por: Fadigas et al. (2009) que analisaram RST de divulgação em educação matemática; Pereira et al. (2011) estudaram a estrutura topológica de RST como um método de análise da eficiência da difusão da informação; e Henrique et al. (2014) utilizaram RST para comparar os títulos de artigos de periódicos de divulgação em educação matemática, em inglês e português. Já Teixeira et al. (2010), Lopes et al. (2015) e Lima-Neto et al. (2018) utilizaram redes semânticas de cliques para analisar a relação entre as palavras (i.e. análise do tipo semântica) que emergem em discursos orais.

Ademais, Fadigas e Pereira (2013) propuseram um conjunto de índices para capturar as propriedades de redes de cliques e um método para caracterizar o fenômeno mundo pequeno nesse tipo de rede. E Grilo et al. (2017) investigaram a robustez de redes semânticas de cliques usando três estratégias de remoção de vértices e encontraram uma fração de remoção na qual as redes cujos vértices foram removidos mantêm o conhecimento da rede original.

Não há trabalhos correlatos para redes de componentes curriculares por conta do seu ineditismo.

$\mathrm{Na}$ Tabela 1, apresentamos um panorama de trabalhos sobre redes semântica de cliques, com os quais podemos perceber comparativamente as congruências entre eles em uma visão mais detalhada, considerando o tipo de discurso, sua aplicação, o tipo de 
análise, o tipo ou método de conexão entre os vértices, o idioma dos discursos e o conjunto resumido de propriedades observadas.

Tabela 1: Panorama de trabalhos sobre redes semânticas.

\begin{tabular}{|c|c|c|c|c|c|c|}
\hline Trabalhos & $\begin{array}{l}\text { Tipos de } \\
\text { discurso }\end{array}$ & Aplicações & $\begin{array}{l}\text { Tipos de } \\
\text { análise }\end{array}$ & $\begin{array}{l}\text { Tipos de } \\
\text { conexão }\end{array}$ & Idiomas & $\begin{array}{l}\text { Conjunto de } \\
\text { propriedades }\end{array}$ \\
\hline $\begin{array}{l}\text { Caldeira et } \\
\text { al. }(2006)\end{array}$ & $\begin{array}{l}\text { Textos } \\
\text { escritos }\end{array}$ & $\begin{array}{l}\text { Investigação } \\
\text { da relação } \\
\text { entre } \\
\text { conceitos }\end{array}$ & Topológica & $\begin{array}{l}\text { Cliques } \\
\text { por } \\
\text { sentença }\end{array}$ & $\begin{array}{c}\text { Inglês } \\
\text { Português }\end{array}$ & $\begin{array}{l}n ; m ;<k> \\
P(k) ; D ; C ; L\end{array}$ \\
\hline $\begin{array}{l}\text { Fadigas et } \\
\text { al. (2009) }\end{array}$ & $\begin{array}{l}\text { Títulos de } \\
\text { artigos de } \\
\text { periódicos }\end{array}$ & $\begin{array}{l}\text { Construção, } \\
\text { descrição e } \\
\text { análise de } \\
\text { redes } \\
\text { semânticas }\end{array}$ & $\begin{array}{l}\text { Semântica } \\
\text { Importância } \\
\text { Topológica }\end{array}$ & $\begin{array}{l}\text { Cliques } \\
\text { por título }\end{array}$ & Português & $\begin{array}{c}n ; m ; t ; p ; \text { comp } \\
\% \text { maior comp.; } \\
\Delta ; k ;<k>; C ; L ; \\
D ; M ; P(k) ; C G ; \\
C P ; C I ; p / n ; p / t ; \\
t / e p\end{array}$ \\
\hline $\begin{array}{l}\text { Teixeira et } \\
\text { al. }(2010)\end{array}$ & $\begin{array}{l}\text { Discursos } \\
\text { orais }\end{array}$ & $\begin{array}{l}\text { Caracterização } \\
\text { de redes } \\
\text { semânticas de } \\
\text { discurso oral }\end{array}$ & $\begin{array}{l}\text { Semântica } \\
\text { Topológica }\end{array}$ & $\begin{array}{l}\text { Cliques } \\
\text { por } \\
\text { sentença }\end{array}$ & Inglês & $F ; I ; I F$ \\
\hline $\begin{array}{l}\text { Pereira et } \\
\text { al. }(2011)\end{array}$ & $\begin{array}{l}\text { Títulos de } \\
\text { artigos de } \\
\text { periódicos } \\
\end{array}$ & $\begin{array}{c}\text { Estudo da } \\
\text { estrutura } \\
\text { topológica } \\
\end{array}$ & $\begin{array}{l}\text { Semântica } \\
\text { Topológica }\end{array}$ & $\begin{array}{l}\text { Cliques } \\
\text { por título }\end{array}$ & $\begin{array}{l}\text { Inglês } \\
\text { Português }\end{array}$ & $\begin{array}{c}k ;<k>; P(k) ; C ; \\
L ; \Delta\end{array}$ \\
\hline $\begin{array}{l}\text { Henrique et } \\
\text { al. (2014) }\end{array}$ & $\begin{array}{l}\text { Títulos de } \\
\text { artigos de } \\
\text { periódicos }\end{array}$ & $\begin{array}{l}\text { Comparação } \\
\text { de títulos em } \\
\text { português e } \\
\text { inglês }\end{array}$ & $\begin{array}{l}\text { Semântica } \\
\text { Topológica }\end{array}$ & $\begin{array}{l}\text { Cliques } \\
\text { por título }\end{array}$ & $\begin{array}{c}\text { Inglês } \\
\text { Português }\end{array}$ & $\begin{array}{c}n ; m ; t ; p ; k ;< \\
k>; P(k) ; C ; L ; \Delta ; \\
\text { comp.; } \\
\% \text { maior comp.; } \\
P c ; p / n ; p / t ; t / n ; \\
N T I\end{array}$ \\
\hline $\begin{array}{l}\text { Lopes et al. } \\
\quad(2015)\end{array}$ & $\begin{array}{l}\text { Discursos } \\
\quad \text { orais }\end{array}$ & $\begin{array}{l}\text { Estudo do } \\
\text { sentido de } \\
\text { corresidência } \\
\text { por meio de } \\
\text { rede semântica } \\
\text { de palavras } \\
\text { evocadas } \\
\end{array}$ & $\begin{array}{l}\text { Semântica } \\
\text { Importância }\end{array}$ & $\begin{array}{l}\text { Cliques } \\
\text { por } \\
\text { palavras } \\
\text { evocadas } \\
\text { por } \\
\text { indivíduo }\end{array}$ & Português & $\begin{array}{c}n ; m ; k ;<k> \\
C G ; C I\end{array}$ \\
\hline $\begin{array}{l}\text { Lima-Neto } \\
\text { et al. } \\
(2018)\end{array}$ & $\begin{array}{l}\text { Discursos } \\
\quad \text { orais }\end{array}$ & $\begin{array}{l}\text { Uso do índice } \\
\text { incidência- } \\
\text { fidelidade para } \\
\text { identificar } \\
\text { redes críticas } \\
\text { de discursos } \\
\text { orais }\end{array}$ & Semântica & $\begin{array}{l}\text { Cliques } \\
\text { por } \\
\text { sentença }\end{array}$ & Português & $I F$ \\
\hline $\begin{array}{l}\text { Fadigas e } \\
\text { Pereira } \\
(2013)\end{array}$ & $\begin{array}{l}\text { Títulos de } \\
\text { artigos de } \\
\text { periódicos }\end{array}$ & $\begin{array}{l}\text { Proposição de } \\
\text { um método } \\
\text { para } \\
\text { caracterizar } \\
\text { redes de } \\
\text { cliques }\end{array}$ & Topológica & $\begin{array}{l}\text { Cliques } \\
\text { por título }\end{array}$ & Inglês & $\begin{array}{c}n ; m ; k ;<k> \\
P(k) ; C ; L ; \Delta ; P c \\
F i\end{array}$ \\
\hline $\begin{array}{l}\text { Grilo et al. } \\
\quad(2017)\end{array}$ & $\begin{array}{l}\text { Títulos de } \\
\text { artigos de } \\
\text { periódicos }\end{array}$ & $\begin{array}{l}\text { Investigação } \\
\text { da robustez de } \\
\text { redes } \\
\text { semânticas de } \\
\text { clique }\end{array}$ & $\begin{array}{l}\text { Topológica } \\
\text { Importância }\end{array}$ & $\begin{array}{l}\text { Cliques } \\
\text { por título }\end{array}$ & Inglês & $\begin{array}{c}C ; C_{\text {on }} ; F ; F(0) ; \\
F r ; F(f) ; f_{p} ; f ; f_{c} \\
f_{c}^{E R} ; f_{c}^{S N T} ;<k>; \\
L ; n ; n(0) ; n(f) ; \\
\quad S(0) ; S(f) ; \\
\quad<T>(f) ; \\
\quad<s>(f)\end{array}$ \\
\hline
\end{tabular}


Legenda: número de vértices $(n=|V|)$, número de arestas $(m=|E|)$, número de títulos $(t)$, número de palavras $(p)$, componentes (comp.), percentagem do maior componente (\% maior comp.), densidade $(\Delta)$, grau médio $(\langle k\rangle)$, coeficiente de aglomeração médio $(C)$, caminho mínimo médio $(L)$, diâmetro $(D)$, eficiências global $\left(E_{\text {global }}\right)$, eficiência local $\left(E_{\text {local }}\right)$, modularidade $(M)$, distribuição de graus $(P(k))$, centralidade de grau $(C G)$, centralidade de proximidade $(C P)$, centralidade de intermediação $(C I)$, vértices de corte $(P c)$, relação número de palavras / número de vértices $(p / n)$, relação número de palavras / número de títulos $(p / t)$, relação títulos / edição do periódico $(t / e p)$, relação títulos / vértices $(t / n)$, número de títulos isolados $(N T I)$, incidência $(I)$, fidelidade $(F)$, índice incidência-fidelidade (IF), índice de fragmentação $(F i)$, conectividade de uma rede com $n$ vértices $\left(C_{o n}\right)$, razão entre os pares não conectados e o número possível de arestas na rede $(F r)$, fração de vértices removidos $(f)$, fragmentação na rede original $(F(0))$, fragmentação na rede após a remoção da fração $f$ de vértices removidos $(F(f)$ ), fração de vértices removidos onde ocorre mudança topológica $\left(f_{p}\right)$, fração crítica de vértices onde a rede separa-se em pequenos componentes $\left(f_{c}\right)$, fração crítica de vértices em uma rede aleatória $\left(f_{c}^{E R}\right)$, fração crítica de vértices em uma rede semântica de títulos $\left(f_{c}^{S N T}\right)$, número de vértices na rede original $(n(0))$, número de vértices na rede após a fração $f$ de vértices removidos $(n(f))$, número de vértices do maior componente da rede original $(S(0))$, número de vértices do maior componente após a fração $f$ de vértices removidos $(S(f))$, tamanho médio dos componentes da rede após a fração $f$ de vértices removidos $(<T\rangle(f))$, tamanho médio dos menores componentes da rede após a fração $f$ de vértices removidos $(<s>(f))$.

\section{Metodologia}

Inicialmente, é importante comentar que uma rede é representada matematicamente por um grafo $G=(V, E)$. Um grafo é uma estrutura matemática que consiste em dois conjuntos: $V$ (finito e não vazio que contem os vértices) e $E$ (relação binária sobre $V$ que contém as arestas) [Gross e Yellen 1999].

Para realizar as análises propostas das redes discutidas neste trabalho, foram usados os seguintes índices: número de vértices $(n=|V|)$, número de arestas $(m=|E|)$, grau médio $(\langle k\rangle)$, coeficiente de aglomeração médio $(C)$ [Watts e Strogatz 1998], caminho mínimo médio $(L)$ [Barabási 2016], diâmetro $(D=\max (L))$, densidade $(\Delta)$, eficiências global $\left(E_{\text {global }}\right)$ e local $\left(E_{\text {local }}\right)$ [Latora e Marchiori 2001], modularidade $(M)$ [Barabási 2016] e distribuição de graus $(P(k))$. Esses índices foram calculados para as redes de ementas e de componentes curriculares e para suas redes aleatórias equivalentes, construídas para caracterizar topologicamente as redes discutidas. Cabe comentar que as redes aleatórias surgem com os trabalhos de Solomonoff e Rapoport (1951) e Erdös e Rényi (1960) e apresentam: uma distribuição de graus que segue a distribuição binomial ou de Poisson quando $n \rightarrow \infty$, uma baixa aglomeração e uma distância curta entre seus vértices. Ademais, foram empregados os seguintes índices para medir a importância dos vértices: centralidade de grau $(C G)$, centralidade de proximidade $(C P)$ e centralidade de intermediação $(C I)$.

O fluxograma do modelo metodológico é apresentado na Figura 2. A execução desse modelo foi realizada para ambas as redes discutidas neste trabalho e a descrição dos processos será apresentada nas próximas seções. 


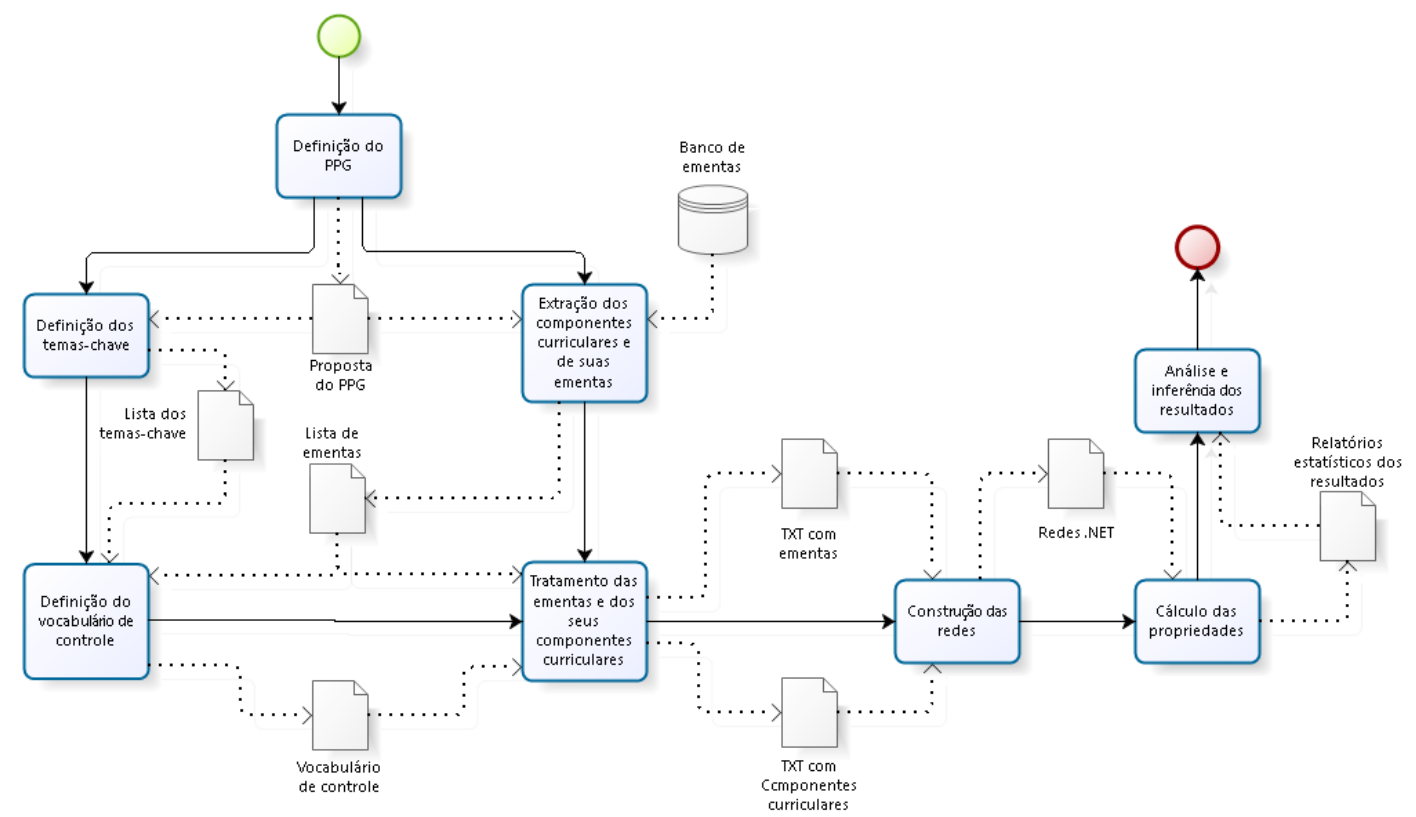

Figura 2: Fluxograma do modelo metodológico.

Para modelagem das redes de ementas e de componentes curriculares foi definido como cenário um PPG, em nível de doutorado, da área de avaliação interdisciplinar da CAPES, conforme o processo "Definição do PPG" (Figura 2). O corpus de análise da sua proposta é constituído pelo texto descritivo da sua área de concentração - 'Modelagem da Geração e Difusão do Conhecimento' e pelos títulos das três linhas de pesquisa - 1 . 'Construção do Conhecimento: Cognição, Linguagens e Informação'; 2. 'Difusão do Conhecimento: Informação, Comunicação e Gestão'; 3. 'Cultura e Conhecimento: Transversalidade, Interseccionalidade e (In)formação’. Essas informações foram obtidas na Plataforma Sucupira.

Para o processo "Extração dos componentes curriculares e de suas ementas" (Figura 2), os componentes curriculares foram obtidos no projeto do PPG investigado e o ementário com 46 ementas foi disponibilizado pelo colegiado do curso, que autorizou a pesquisa por meio de assinatura da Carta de Anuência. Vale salientar que este trabalho foi apreciado e aprovado pelo Comitê de Ética em Pesquisa da Escola de Nutrição da Universidade Federal da Bahia (Número do parecer: 2.487.366).

\subsection{Rede de ementas}

Os processos "Definição dos temas-chave" e "Definição do vocabulário de controle" (Figura 2) foram realizados de forma manual, seguindo as etapas:

1. Pré-análise do corpus a partir de leitura para familiarização com o texto descritivo da área de concentração, títulos das linhas de pesquisa e ementas.

2. Identificação de temas-chave no texto descritivo da área de concentração e nos títulos das linhas de pesquisa que representassem o conteúdo teórico ou teóricometodológico da proposta de aprendizagem do PPG investigado. Recomenda-se àqueles que queiram aplicar a metodologia proposta que instaure um comitê composto por um número ímpar de membros especialistas do PPG e com, no 
mínimo, três membros para a identificação dos temas-chave a fim de evitar vieses, assim como foi feito neste trabalho.

3. Identificação de palavras relacionadas semanticamente aos temas-chave nas ementas.

4. Quantificação da frequência de aparição das palavras relacionadas aos temaschave nas ementas a fim de selecionar aquelas de maior ocorrência, sendo essas escolhidas para representar os temas-chave.

Após essas etapas, foram identificados 15 temas-chave e palavras relacionadas que compõem o vocabulário de controle usado no tratamento das ementas (Tabela 2). Cabe ressaltar que os temas-chave "conhecimento", "construção do conhecimento", "difusão do conhecimento" e "geração do conhecimento", apesar de estarem estreitamente relacionados entre si, possuem significados distintos, e, por isso, foram agrupados em categorias distintas.

Tabela 2: Vocabulário de controle, frequência de aparição das palavras relacionadas aos temas-chave nas ementas entre parêntese e as palavras de maior ocorrência por tema-chave em negrito.

\begin{tabular}{|c|c|c|}
\hline \multicolumn{2}{|c|}{ TEMAS-CHAVE (TC) } & PALAVRAS RELACIONADAS \\
\hline TC1 & Metodologia & $\begin{array}{l}\text { Método (7), metodologias (2), aspectos metodológicos (1), metodologias } \\
\text { participativas (1), recorte teórico-metodológico (1) }\end{array}$ \\
\hline TC2 & Cognição & $\begin{array}{l}\text { Análise cognitiva (2), ciências cognitivas (2), analista cognitivo (1), } \\
\text { cognição (1), cognólogo (1), processos cognitivos (1) }\end{array}$ \\
\hline TC3 & Complexidade & Complexidade (5), redes complexas (1), sistemas complexos (1) \\
\hline TC4 & Comunicação & $\begin{array}{l}\text { Comunicação (2), canais de comunicação (1), cenário comunicativo (1), } \\
\text { comunicação não verbal (1), relações comunicativas (1) }\end{array}$ \\
\hline TC5 & Ciência & $\begin{array}{l}\text { Ciência (7), desenvolvimento científico (1), difusão da ciência (1), } \\
\text { disseminação da ciência (1), divulgação da ciência (1), invenção (1), } \\
\text { científica (1), pesquisa científica (1), popularização da ciência (1), } \\
\text { produção científica (1) }\end{array}$ \\
\hline TC6 & Tecnologia & $\begin{array}{l}\text { Tecnologia (4), desenvolvimento tecnológico (1), dimensão tecnológica } \\
\text { (1), inovação tecnológica (1), tecnologias da comunicação (1), tecnologias } \\
\text { da informação (2), transferência de tecnologia (1) }\end{array}$ \\
\hline TC7 & Conhecimento & $\begin{array}{l}\text { Conhecimento (11), gestão do conhecimento (3), padronização do } \\
\text { conhecimento (2), bases de conhecimento (1), campos de conhecimento } \\
\text { (1), controle do conhecimento (1), disseminação do conhecimento (1), } \\
\text { divulgação do conhecimento (1), popularização do conhecimento (1) }\end{array}$ \\
\hline TC8 & $\begin{array}{l}\text { Construção do } \\
\text { conhecimento }\end{array}$ & Construção do conhecimento (3) \\
\hline TC9 & Cultura & $\begin{array}{l}\text { Cultura (4), cibercultura (2), abordagens culturais (1), antropologia } \\
\text { cultural (1), contextos culturais (1), cultura brasileira (1), culturalismo (1), } \\
\text { diversidade cultural (1), indústria cultural (1), matrizes culturais (1), } \\
\text { pluralismo cultural (1), politicas culturais (1), produção cultural (1) }\end{array}$ \\
\hline TC10 & $\begin{array}{l}\text { Difusão do } \\
\text { conhecimento }\end{array}$ & Difusão do conhecimento (11) \\
\hline TC11 & Epistemologia & $\begin{array}{l}\text { Epistemologia (1), bases epistemológicas (1), correntes epistemológicas } \\
\text { (1), escolhas epistemológicas (1) }\end{array}$ \\
\hline $\mathrm{TC} 12$ & $\begin{array}{l}\text { Geração do } \\
\text { conhecimento }\end{array}$ & Geração do conhecimento (2) \\
\hline TC13 & Informação & Informação (3), disseminação da informação (1) \\
\hline $\mathrm{TC} 14$ & Linguagem & Linguagem (5) \\
\hline TC15 & Modelagem & Modelo (9), modelagem (3), modelagem computacional (2) \\
\hline
\end{tabular}


Na construção de uma rede semântica de cliques baseada em ementas, cada ementa é considerada uma sentença de um discurso escrito que, por sua vez, forma uma clique. As palavras de cada ementa são os vértices de uma clique e as arestas são as conexões entre as palavras que aparecem na mesma ementa. As palavras em comum às ementas são os vértices em comum às cliques, que fazem a justaposição e/ou sobreposição das cliques, formando a rede de ementas (Figura 3).

Os processos de justaposição e sobreposição definidos em Pereira e Fadigas (2013) pretendem colaborar com a análise da redução de palavras de um discurso em relação à quantidade de vértices da rede semântica desse discurso. Ementas que possuem uma quantidade $(\geq 2)$ de palavras iguais são conectadas por sobreposição. É importante definir o percentual máximo de vértices em comum e associá-lo quantitativamente ao conceito de coesão. Todavia, o percentual de vértices sobrepostos no processo de sobreposição entre pares de ementas que indique semelhança ou igualdade entre as ementas não foi definido neste estudo e será discutido em trabalhos futuros.

A Figura 3 ilustra a formação de uma rede semântica de cliques resultante de duas ementas dos componentes curriculares: 'EDCA93 - Gestão do Conhecimento e Aprendizagem Colaborativa' e 'EDCA94 - Infoeducação e Educação à Distância'. As palavras "processo", "difusão do conhecimento" e "geração do conhecimento" são as palavras em comuns às ementas, que atuam como vértices de conexão fazendo a sobreposição entre as duas cliques.

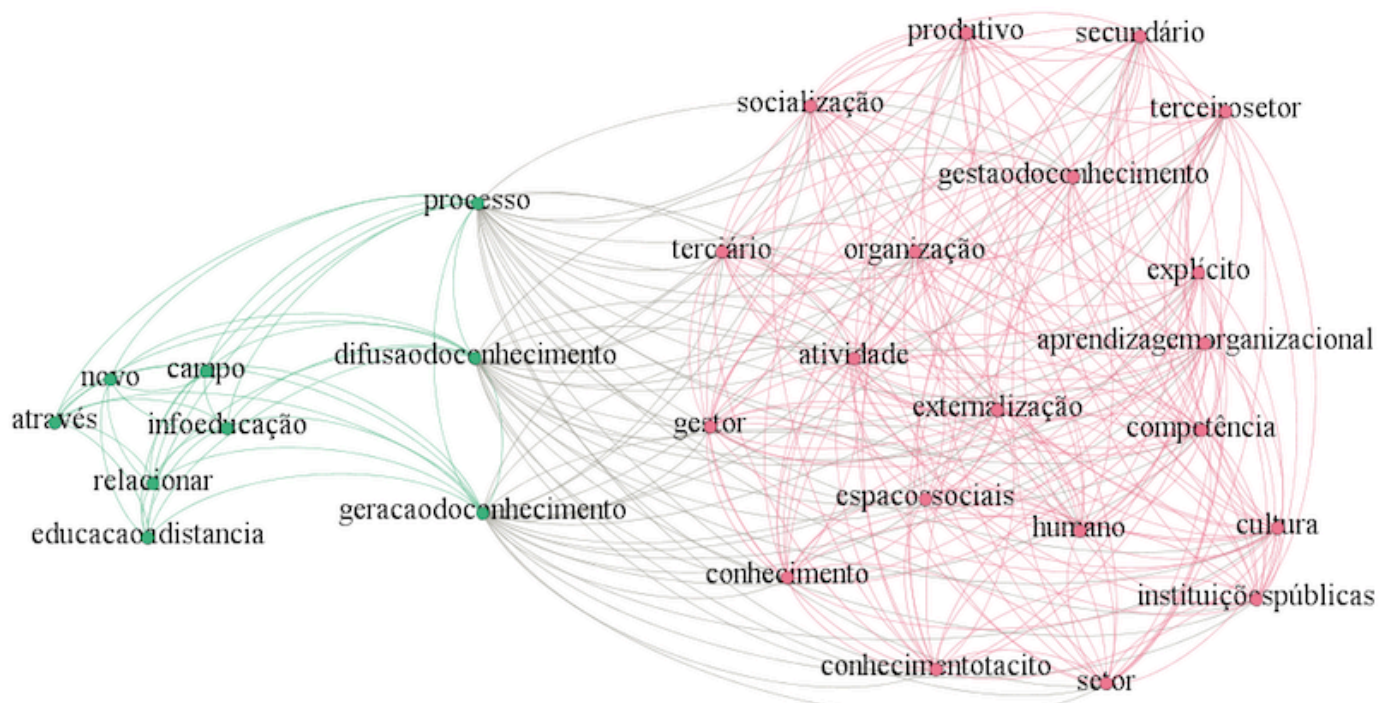

Figura 3: Exemplo de formação da rede de ementas considerando duas ementas de componentes curriculares.

Os processos de "Tratamento das ementas e dos seus componentes curriculares" e "Construção das redes" (Figura 2) foram realizados conforme as etapas a seguir:

1. União das ementas em um único discurso, sendo cada ementa inserida em uma linha de um arquivo de formato . txt.

2. Tratamento manual das ementas, que consiste na aplicação de 11 regras gerais propostas por Pereira et al. (2011), e aplicação de uma nova regra, devido a uma especificidade deste trabalho, a saber: em alguns casos, foi necessária a introdução 
das palavras de maior ocorrência por temas-chave nas ementas que tratavam dos temas-chave, mas que não as continham. Isto propiciou a conexão entre as ementas (i.e. cliques) que tratavam do mesmo tema-chave. Por exemplo, havia uma ementa que explanava sobre vários tipos de métodos (método analítico simplex, método de Householder e métodos estocásticos), e, seguindo uma das regras do tratamento manual, essas palavras foram convertidas em "métodoanalíticosimplex", "métododehouseholder" e "métodosestocásticos", respectivamente. Como nessa ementa não aparecia a palavra "método" sozinha, ela não iria se conectar a outras que tratassem do tema "T1: Metodologia" (Tabela 2), fazendo-se necessária a introdução da palavra "método" na ementa. Outra situação para aplicação dessa nova regra ocorre quando a ementa apresenta pelo menos uma palavra relacionada ao tema-chave, segundo o vocabulário de controle (Tabela 2), mas não apresenta a palavra de maior ocorrência, sendo essa introduzida na ementa com o intuito de proporcionar a conexão das cliques por temas-chave.

3. No tratamento computacional, as ementas passam por um conjunto de programas da UNITEX [Paumier 2008] para classificação, modificação e eliminação de palavras, quando necessária. Também foi utilizado o conjunto de ferramentas computacionais desenvolvido por Caldeira et al. (2005) que permite, dentre outras coisas, identificar a classe gramatical de cada palavra da rede. Utilizando essas ferramentas, foi feita a exclusão das palavras gramaticais e mantiveram-se as palavras lexicais. Ao final do tratamento computacional foram gerados dois arquivos de formato . txt (um contendo o vocabulário e a classificação gramatical das palavras; e outro com os pares de palavras, frequência de aparição das palavras e dos pares nas ementas, e os valores do índice incidência-fidelidade de cada par de palavras) e um arquivo no formato . net, que consiste na rede de ementas.

O processo de "Cálculo das propriedades" (Figura 2) foi realizado com o auxílio dos softwares Gephi (versão 0.9.1), Pajek (versão 5.05) e SCNTools (versão 1.4.8), e o processo de "Análise e inferência dos resultados" (Figura 2) foi realizado com os resultados dos cálculos supracitados. Ademais, foi realizada a análise das comunidades da rede de ementas para apoio da análise de conteúdo do ementário.

Finalmente, foi aplicado o índice incidência-fidelidade $(I F)$ na rede de ementas a fim de verificar o fenômeno rede crítica seguindo a proposta de Teixeira et al. (2010). A rede crítica identificada foi caracterizada topologicamente pelos mesmos índices adotados para análise da rede original.

\subsection{Rede de componentes curriculares}

A rede de componentes curriculares é formada por vértices que consistem em componentes curriculares e por arestas que são os temas-chave em comum aos componentes curriculares. Esses temas-chave foram extraídos do texto da área de concentração e dos títulos das linhas de pesquisas e também identificados nas ementas dos componentes curriculares. Temas-chave em comum a dois ou mais componentes curriculares os conectam.

Não há vértices repetidos na rede de componentes curriculares porque não há componentes curriculares repetidos na matriz curricular de um curso. Por meio da rede 
de componentes curriculares é possível identificar grupos de componentes curriculares (comunidades) que compartilham os mesmos temas-chave. A partir disto, podemos comparar as ementas dos componentes curriculares de uma mesma comunidade a fim de identificar disciplinas com abordagens semelhantes e, assim, identificar possíveis duplicidades de disciplinas no currículo, as quais poderiam ser revistas ou excluídas em uma reforma curricular. A análise comparativa das ementas de disciplinas por comunidade seria uma forma de otimizar a avaliação de um currículo, pois a análise por comunidades reduz o corpus de análise. Além disto, caso haja um componente curricular isolado na rede, isto indica que este não se relaciona com os demais componentes do currículo, então os especialistas do curso deveriam avaliar a sua exclusão ou revisão.

Apesar dos processos metodológicos apresentados até então serem similares para a rede de componentes curriculares, algumas especificidades serão destacadas a seguir, e.g. as regras de construção da rede.

A identificação dos temas-chave nas ementas permitiu o agrupamento dos componentes curriculares por temas-chave (Tabela 3). Para a construção da rede de componentes curriculares, os componentes curriculares de cada grupo de temas-chave foram conectados entre si constituindo uma clique.

Nessa rede, os vértices representam os componentes curriculares e as arestas são as conexões entre eles estabelecidas pelo compartilhamento de temas-chave em comum. As arestas foram ponderadas quando havia o compartilhamento de dois ou mais temaschave por dois componentes curriculares. Dos 46 componentes curriculares que compõe a matriz curricular do PPG investigado, 40 se conectaram por temas-chave em comum e seis não se conectaram por nenhum tema-chave, a saber: EDCB01; EDCB08; EDCB11; EDCB12; EDCB13; e EDCE33.

Tabela 3: Agrupamento dos componentes curriculares por temas-chave.

\begin{tabular}{|c|c|l|}
\hline \multicolumn{2}{|c|}{ TEMAS-CHAVE (TC) } & CÓDIGOS DOS COMPONENTES CURRICULARES \\
\hline TC1 & Metodologia & $\begin{array}{l}\text { EDCA91; EDCA86; EDCA98; EDCA99; EDCB04; EDCB09; } \\
\text { EDCB76; EDCB14; EDCH67; EDCH83 }\end{array}$ \\
\hline TC2 & Cognição & EDCE31; EDCC42 \\
\hline TC3 & Complexidade & EDCA85; EDCA87; EDCA89; EDCB05; EDCB09; EDCE46 \\
\hline TC4 & Comunicação & EDCB07; EDCB10; EDCJ38 \\
\hline TC5 & Ciência & EDCA85; EDCA89; EDCA92; EDCB05; EDCB06; EDCJ78; EDCE47 \\
\hline TC6 & Tecnologia & EDCA90; EDCA92; EDCB06; EDCH10 \\
\hline TC7 & Conhecimento & $\begin{array}{l}\text { EDCA85; EDCA88; EDCA89; EDCE30; EDCA92; EDCA93; } \\
\text { EDCB09; EDCC42; EDCB07; EDCJ78 }\end{array}$ \\
\hline TC8 & $\begin{array}{c}\text { Construção do } \\
\text { conhecimento }\end{array}$ & EDCA89; EDCH68; EDCA92 \\
\hline TC9 & Cultura & EDCE32; EDCB07; EDCB09; EDCA93 \\
\hline TC10 & $\begin{array}{c}\text { Difusão do } \\
\text { conhecimento }\end{array}$ & $\begin{array}{l}\text { EDCA89; EDCA90; EDCA93; EDCA94; EDCA95; EDCB09; } \\
\text { EDCC42; EDCC51; EDCE32; EDCH10; EDCJ78 }\end{array}$ \\
\hline TC11 & Epistemologia & EDCB09; EDCH83 \\
\hline TC12 & $\begin{array}{c}\text { Geração do } \\
\text { conhecimento }\end{array}$ & EDCA93; EDCA94 \\
\hline TC13 & Informação & EDCA90; EDCB07; EDCB10; EDCB02 \\
\hline TC14 & Linguagem & EDCA96; EDCA97; EDCB10; EDCC49; FISB39 \\
\hline TC15 & Modelagem & $\begin{array}{l}\text { EDCA85; EDCA88; EDCA89; EDCA91; EDCA92; EDCA95; } \\
\text { EDCB03; EDCB04; EDCB76; EDCE46 }\end{array}$ \\
\hline
\end{tabular}




\section{Resultados e discussão}

\subsection{Rede de ementas}

Na rede de ementas, os vértices são as palavras empregadas nas ementas para descrever o conteúdo teórico (conceitual) ou teórico-metodológico (conceitual/ procedimental) dos componentes curriculares. Desta forma, os vértices representam conceitos e as arestas representam as conexões entre esses conceitos. Para reforçar essa afirmação, em revisão sistemática sobre redes semânticas, Rosa (2016) observou que, para a maioria dos trabalhos analisados (80\%), um vértice de uma rede semântica representa conceitos ou objetos e as arestas representam as relações entre eles.

A rede de ementas do PPG investigado é constituída por 766 vértices e 17.201 arestas. Os vértices estão conectados em média a aproximadamente 45 outros vértices ( $<$ $k>=44,91$ ). Isto sugere que as ementas apresentam um vocabulário restrito para expressar os conhecimentos pretendidos, em torno de 45 palavras.

Apesar da rede de ementas ser considerada esparsa $(\Delta=0,059)$, sua densidade é maior que as observadas em RST [Pereira et al. 2016]. Isto ocorre pelo fato de haver menor diversidade de palavras nas ementas do que entre as palavras dos títulos de artigos científicos. Menor diversidade de palavras pode significar palavras repetidas em diferentes ementas, as quais fazem os processos de justaposição e sobreposição entre as cliques. E quanto mais justaposições e sobreposições ocorrem, maior densidade e maior coerência e consistência entre as ementas, ou seja, essas compartilham mais conceitos em comum.

O coeficiente de aglomeração médio $(C)$ é um índice que mede o quanto os vértices vizinhos de um vértice estão conectados entre si. No caso da rede investigada, esse indicador é considerado alto $(C=0,92)$, o que indica que os vizinhos dos vértices têm muitos vizinhos entre si, havendo muitas conexões entre os vértices da rede. Isto pode ser explicado pelo próprio método de construção de redes semânticas de cliques e também pela grande quantidade de vértices em comum às ementas. Assim, o coeficiente de aglomeração médio alto pode ser outro indicativo de menor diversidade de palavras e maior ocorrência de justaposições e sobreposições.

O diâmetro da rede investigada é igual a quatro $(D=4)$. O caminho mínimo médio $(L)$ informa que, em média, a distância entre os vértices é de $L=2,302$, o que significa que os vértices são muito próximos. Isto também acontece pela quantidade de justaposições e sobreposições entre as ementas, reflexo do maior compartilhamento de conceitos em comum, o que pode ser um indício de interdisciplinaridade.

Quanto à caracterização topológica, pode-se afirmar que a rede de ementas $(R E)$ apresenta o fenômeno mundo pequeno, segundo o método de Watts e Strogatz (1998), uma vez que possui coeficiente de aglomeração médio elevado em relação ao da rede aleatória $(R A)$ correspondente $\left(C_{R E}=0,92 \gg C_{R A}=0,03\right)$ e caminho mínimo médio similar ao da rede aleatória correspondente $\left(L_{R E}=2,302 \sim L_{R A}=2,382\right)$. Além disto, também foram observadas outras condições necessárias para que a rede investigada fosse considerada rede de mundo pequeno, a saber: não dirigida, não ponderada, simples, esparsa e conectada (i.e. possui apenas um componente) [Watts 1999]. O fenômeno mundo pequeno também foi identificado pelo método de Latora e Marchiori (2001), cujos resultados das eficiências foram $E_{\text {global }}=0,46 \mathrm{e} E_{\text {local }}=0,95$. A distribuição de graus 
também foi verificada, mas não apresentou nenhuma distribuição característica, como a binominal ou lei de potência.

A distribuição do tamanho das cliques mostrou que doze ementas concentram a maior quantidade de vértices, das quais quatro ementas possuem 17 vértices, quatro com 19 vértices e quatro com 21 vértices (Figura 4). Isto sugere que o tamanho das cliques tem uma relação direta com o grau médio da rede.

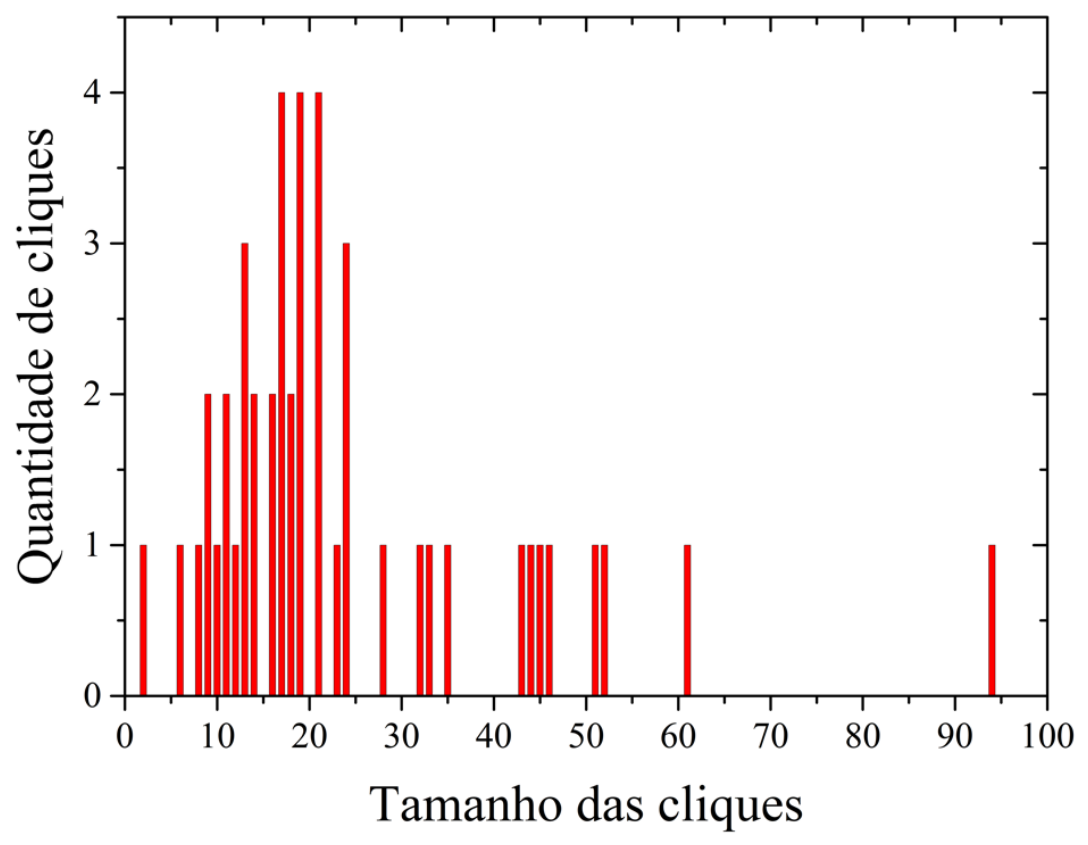

Figura 4. Distribuição do tamanho das cliques/ementas.

Considerando a análise de redes sociais, investigou-se também a importância dos vértices por meio das centralidades de grau, de proximidade e de intermediação. Os 13 vértices da rede de ementas mais importantes em termo de centralidade de grau, em ordem decrescente, são: "conhecimento", "teoria", "abordagem", "difusão do conhecimento", "sociedade", "análise", "processo", "complexidade", "pesquisa", "aplicação", "rede", "método" e "modelo". Dentre esses conceitos, cinco representam temas-chave ("conhecimento", "difusão do conhecimento", "complexidade", "método" e "modelo"), e os outros, apesar de conceitualmente não representarem a proposta do PPG, possuem significados relevantes para um curso de doutorado ("teoria", "abordagem", "sociedade", "análise", "processo", pesquisa", "aplicação" e "rede").

$\mathrm{Na}$ Tabela 4, são apresentados apenas os vértices que representam as palavras de maior ocorrência por temas-chave na rede de ementas.

Do ponto de vista da importância dos vértices, que são as palavras de maior ocorrência por temas-chave nas ementas, pode-se observar que o vértice de maior centralidade de grau é "conhecimento" $(C G=277)$, seguido pelo vértice "difusão do conhecimento" ( $C G=240$ ) (Tabela 4). Parece razoável afirmar que esse fato é resultante da própria área de concentração em que o PPG está inserido, indicando assim que existe coerência e consistência entre a proposta do PPG e seu ementário em relação aos temaschave "T7: Conhecimento" e "T10: Difusão do conhecimento". 
Tabela 4: Medidas de centralidades dos vértices que são as palavras de maior ocorrência por temas-chave (TC).

\begin{tabular}{|c|l|c|c|c|}
\hline TC & \multicolumn{1}{|c|}{ VÉRTICES } & CG & $C P$ & $C I$ \\
\hline TC7 & Conhecimento & 277 & 0,6105 & 0,0720 \\
\hline TC10 & Difusão do conhecimento & 240 & 0,5930 & 0,0508 \\
\hline TC3 & Complexidade & 210 & 0,5795 & 0,0306 \\
\hline TC1 & Método & 190 & 0,5709 & 0,0585 \\
\hline TC15 & Modelo & 179 & 0,5429 & 0,0353 \\
\hline TC5 & Ciência & 150 & 0,5488 & 0,0172 \\
\hline TC14 & Linguagem & 143 & 0,5422 & 0,0305 \\
\hline TC9 & Cultura & 132 & 0,5387 & 0,0125 \\
\hline TC11 & Epistemologia & 89 & 0,5222 & 0,0000 \\
\hline TC13 & Informação & 76 & 0,4713 & 0,0054 \\
\hline TC8 & Construção do conhecimento & 67 & 0,4926 & 0,0021 \\
\hline TC4 & Comunicação & 60 & 0,4468 & 0,0022 \\
\hline TC6 & Tecnologia & 48 & 0,4885 & 0,0031 \\
\hline TC12 & Geração do conhecimento & 29 & 0,4279 & 0,0003 \\
\hline TC2 & Análise cognitiva & 25 & 0,4540 & 0,0003 \\
\hline
\end{tabular}

Por outro lado, as palavras "análise cognitiva" $(C G=25)$ e "geração do conhecimento" ( $C G=29)$ são os vértices que tiveram menor centralidade de grau, o que pode estar relacionado ao fato de aparecerem em apenas duas disciplinas (Tabela 4). Essa constatação sugere que esses são os temas-chave menos abordados pelos componentes curriculares em comparação aos outros, ou seja, conceitos menos representativos do discurso do PPG investigado. Porém, deveriam ganhar maior destaque nas ementas, uma vez que "geração do conhecimento" é almejada pela área de concentração do PPG investigado e "análise cognitiva" é o tema-chave central da linha de pesquisa três.

A centralidade de proximidade está relacionada com a distância total de um vértice em relação a todos os demais vértices do grafo [Freeman 1978/79]. Na rede de ementas, os vértices de maior centralidade de proximidade são os conceitos mais próximos, mais centrais aos outros no conjunto de ementas. Na rede investigada, os conceitos mais próximos aos outros são "conhecimento" $(C P=0,6105)$ e "difusão do conhecimento" ( $C P=0,5930)$, respectivamente (Tabela 4), o que já era de se esperar uma vez que esses vértices representam os temas-chave centrais do PPG investigado.

Já a centralidade de intermediação mede quantos caminhos mais curtos entre todos os pares de vértices do grafo passam por um determinado vértice [Freeman 1978/79]. Este índice avalia a frequência de ocorrência de um determinado vértice entre pares de outros vértices em caminhos mais curtos que os conectam. Na rede de ementas, os vértices com maior centralidade de intermediação são "conhecimento" $(C I=0,0720)$, "método" $(C I=0,0585)$ e "difusão do conhecimento" $(C I=0,0508)$. Estes vértices estabelecem pontes entre vários outros conceitos, promovendo o relacionamento entre eles na rede de ementas e, desta maneira, "conhecimento", "método" e "difusão do conhecimento" compõem o cerne conceitual das ementas (Tabela 4).

$\mathrm{Na}$ rede de ementas, foram observadas 10 comunidades com o índice de modularidade igual a 0,619 (Figura 5). Newman e Girvan (2004) definem comunidades como grupos de vértices densamente conectados. Em redes semânticas, os vértices que compõem as comunidades formam grupos de palavras bem integrados ou semanticamente relacionados. Esse fato também é observado em redes semânticas de cliques, mas, não 
necessariamente, as comunidades refletem as cliques, pois as justaposições e sobreposições entre as cliques aumentam a densidade das comunidades.

Observa-se na Figura 5 que a comunidade em azul claro agrupa os seguintes vértices: "conhecimento", "difusão do conhecimento", "geração do conhecimento", "construção do conhecimento" e "cognição". Essas palavras possuem significados distintos, mas correlacionados entre si, e fazem parte do processo de "Modelagem da Geração e Difusão do Conhecimento", área de concentração do PPG investigado. Por isso, essa comunidade representa um importante núcleo semântico do PPG investigado. Também foi observado que os vértices que representam os temas-chave "difusão do conhecimento", "ciência", "complexidade" e "tecnologia" são vértices que atuam como "pontes" entre comunidades. Os conceitos responsáveis por conectar as comunidades de uma rede de ementas demonstram as conexões entre elas, o que possibilita a extração de contextos semânticos que auxiliam no melhor entendimento desses conceitos dentro da proposta do PPG investigado. As conexões entre as comunidades reforçam, se não a ideia da interdisciplinaridade, no mínimo, o pensamento multidisciplinar, podendo servir de apoio para uma melhor elaboração das ementas e promoção de interações entre as disciplinas de um curso.

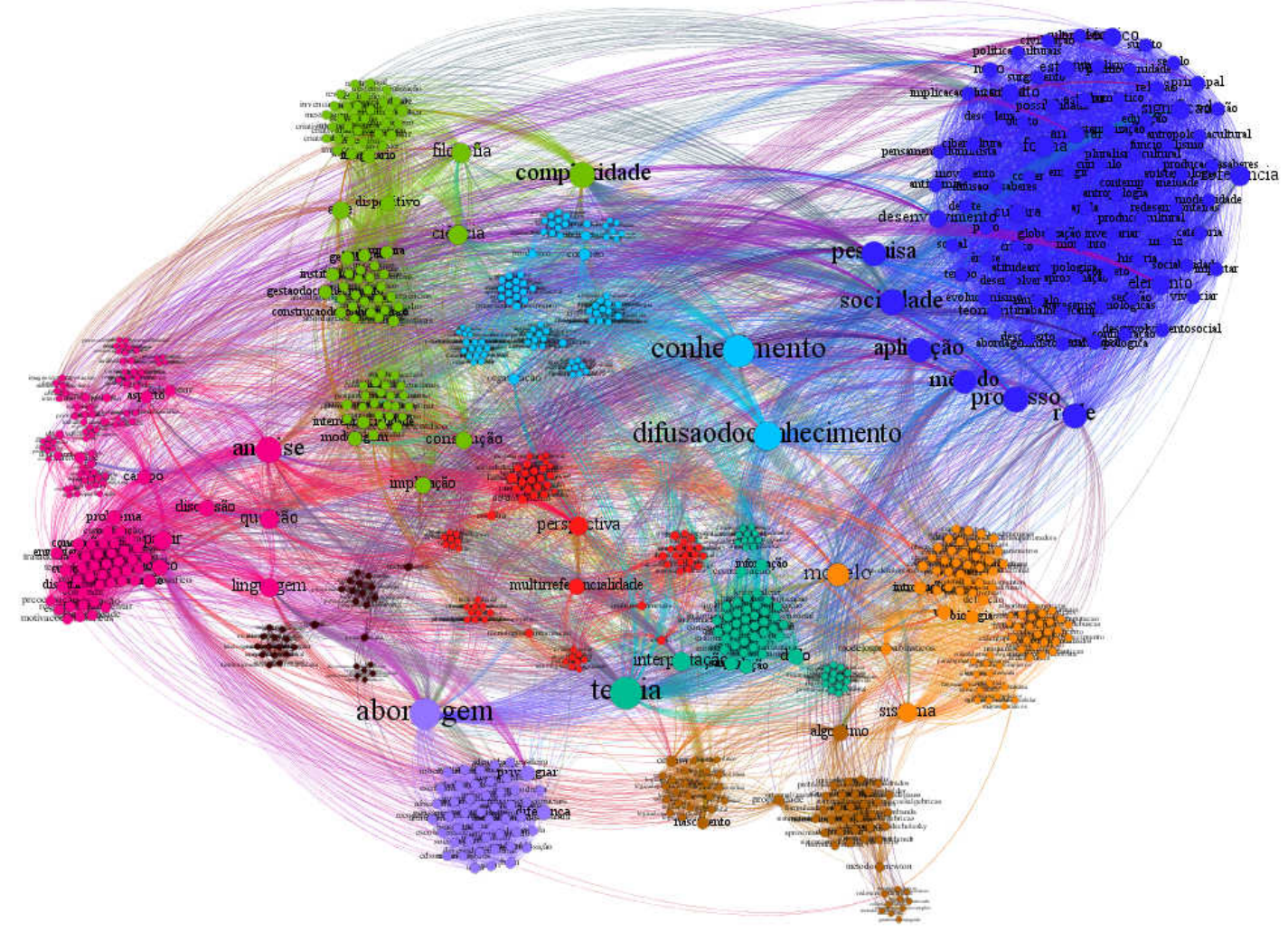

Figura 5. Rede de ementas com destaque para os vértices de maior centralidade de grau e distribuição espacial por comunidades.

Para melhor compreensão do discurso da proposta de aprendizagem do PPG representado pelo seu ementário, a rede de ementas foi filtrada utilizando o índice incidência-fidelidade $(I F)$. Segundo Teixeira et al. (2010), os pares de palavras cuja associação é pouco significativa, quando incluídos em uma rede semântica, mascaram a estrutura formada pelas associações mais fortes, as quais são mais relevantes na representação do discurso. Daí se propõe a aplicação do filtro supracitado para obtenção 
de uma rede semântica que melhor represente um discurso. Ainda segundo esses autores, as redes semânticas sem a aplicação desse filtro contêm muita informação irrelevante, o que dificulta uma inspeção visual e o entendimento do discurso. Após a aplicação do filtro, a rede possui o máximo de informação com mínimo de resíduo, ainda representando o sistema de palavras representativas do discurso.

$O$ índice $I F$ pondera as arestas de uma rede semântica por meio da frequência de aparição de cada aresta (par de palavras) nas unidades de significado que, neste caso, são as ementas. A incidência considera a frequência de aparição no texto todo de um dado par de palavras, enquanto que a fidelidade considera a frequência de aparição de um dado par de palavras em todo contexto em que pelo menos uma palavra do par foi evocada [Teixeira et al. 2010].

Incidência-fidelidade limite $\left(I F_{L}\right)$ consiste em valores limites de incidênciafidelidade determinados para o processo de filtragem de redes semânticas. Sendo assim, à medida que aumenta o valor de $I F_{L}$, arestas com valores de $I F<I F_{L}$ são descartadas, ou seja, pares de palavras com $I F<I F_{L}$ são removidos, ficando na rede apenas pares que possuem valores iguais ou superiores à incidência-fidelidade limite, ou seja, $I F \leq$ $I F_{L}$. Ao longo desse processo de filtragem, verifica-se que, em determinado valor de incidência-fidelidade, $I F=I F_{c}$, a rede obtém uma configuração com o máximo de informação e o mínimo de resíduo, denominada rede crítica [Teixeira et al. 2010]. Nessa configuração, a rede exibe propriedades interessantes, tais como uma alta conectividade, diâmetro e presença de comunidades robustas. A partir desse ponto, qualquer incremento no valor de $I F_{\mathrm{L}}$ gera uma mudança brusca nos valores dos índices da rede. A Tabela 5 mostra o comportamento de alguns índices de redes em função de alguns valores de $I F_{L}$.

Tabela 5: Valores das redes filtradas da rede de ementas original após aplicação dos índices de incidência-fidelidade limites.

\begin{tabular}{|c|c|c|c|c|c|c|c|c|c|c|c|}
\hline $\mathrm{IF}_{\mathrm{L}}$ & $\mathrm{V}$ & $\mathrm{E}$ & $\mathrm{D}$ & $\mathrm{C}$ & $\mathrm{L}$ & $<k>$ & $\Delta$ & $\mathrm{PNC}$ & $\mathrm{V}_{\mathrm{N}}$ & $E_{N}$ & $\Delta_{V, \boldsymbol{E}}$ \\
\hline 0,0010 & 766 & 17201 & 4 & 0,9162 & 2,3022 & 44,9112 & 0,05871 & 0 & 1,0000 & 1,0000 & 0,0000 \\
\hline 0,0030 & 766 & 15479 & 5 & 0,8942 & 2,5283 & 40,4151 & 0,05283 & 0 & 1,0000 & 0,8999 & 0,1001 \\
\hline 0,0050 & 765 & 13247 & 6 & 0,8896 & 3,0233 & 34,6327 & 0,04533 & 0 & 0,9987 & 0,7701 & 0,2286 \\
\hline 0,0070 & 765 & 11993 & 6 & 0,8887 & 3,4032 & 31,3542 & 0,04104 & 0 & 0,9987 & 0,6972 & 0,3015 \\
\hline 0,0090 & 764 & 10386 & 10 & 0,8882 & 4,6414 & 27,1885 & 0,03563 & 5299 & 0,9974 & 0,6038 & 0,3936 \\
\hline $\mathbf{0 , 0 1 0 0}$ & $\mathbf{7 6 4}$ & $\mathbf{1 0 3 5 5}$ & $\mathbf{1 2}$ & $\mathbf{0 , 8 8 7 6}$ & $\mathbf{4 , 8 5 6 0}$ & $\mathbf{2 7 , 1 0 7 3}$ & $\mathbf{0 , 0 3 5 5 3}$ & $\mathbf{5 2 9 9}$ & $\mathbf{0 , 9 9 7 4}$ & $\mathbf{0 , 6 0 2 0}$ & $\mathbf{0 , 3 9 5 4}$ \\
\hline $\mathbf{0 , 0 1 2 0}$ & $\mathbf{7 3 7}$ & $\mathbf{7 7 1 6}$ & $\mathbf{8}$ & $\mathbf{0 , 9 1 1 3}$ & $\mathbf{2 , 1 3 1 6}$ & $\mathbf{2 0 , 9 3 8 9}$ & $\mathbf{0 , 0 2 8 4 5}$ & $\mathbf{2 5 8 8 9 0}$ & $\mathbf{0 , 9 6 2 1}$ & $\mathbf{0 , 4 4 8 6}$ & $\mathbf{0 , 5 1 3 6}$ \\
\hline 0,0140 & 730 & 7667 & 10 & 0,9208 & 2,0374 & 21,0055 & 0,02881 & 255497 & 0,9530 & 0,4457 & 0,5073 \\
\hline 0,0160 & 720 & 7619 & 9 & 0,9285 & 1,5315 & 21,1639 & 0,02944 & 249699 & 0,9399 & 0,4429 & 0,4970 \\
\hline 0,0210 & 713 & 7571 & 7 & 0,9240 & 1,1731 & 21,2370 & 0,02983 & 245719 & 0,9308 & 0,4401 & 0,4907 \\
\hline 0,0280 & 62 & 55 & 6 & 0,1919 & 2,3000 & 1,7742 & 0,02909 & 1761 & 0,0809 & 0,0032 & 0,0777 \\
\hline 0,0390 & 33 & 24 & 2 & 0,3030 & 1,0400 & 1,4546 & 0,04545 & 503 & 0,0431 & 0,0014 & 0,0417 \\
\hline 0,0480 & 8 & 4 & 1 & 0,0000 & 1,0000 & 1,0000 & 0,14286 & 24 & 0,0104 & 0,0002 & 0,0102 \\
\hline 0,0520 & 2 & 1 & 1 & 0,0000 & 1,0000 & 1,0000 & 1,00000 & 0 & 0,0026 & 0,0001 & 0,0026 \\
\hline
\end{tabular}

Legenda: $\mathrm{PNC}=$ pares não conectados; $\boldsymbol{V}_{\boldsymbol{N}}=$ vértices normalizados; $\boldsymbol{E}_{\boldsymbol{N}}=$ arestas normalizadas; $\Delta_{V, \boldsymbol{E}}=$ diferença entre vértices e arestas normalizados. 
Após aplicação do filtro incidência-fidelidade na rede de ementas, observou-se a presença do fenômeno crítico em $I F_{c}=1 \times 10^{-2}$, devido ao comportamento do caminho mínimo médio em função de $I F_{L}$. No gráfico da Figura 6 , observa-se que, a partir de $I F_{L}=$ $1 \times 10^{-2}$, o valor do caminho mínimo médio cai bruscamente. De acordo com Teixeira et al. (2010), a rede crítica também acontece quando a diferença entre vértices e arestas é a maior possível. Para esse cálculo, consideramos os valores normalizados de vértices $\left(V_{N}\right)$ e arestas $\left(E_{N}\right)$, ou seja, a diferença é dada por $\Delta_{V, E}=V_{N}-E_{N}$. Neste trabalho, não obstante esse indicador ter um alto valor em $I F_{C}=1 \times 10^{-2}\left(\Delta_{V, E}=0,39\right)$, essa configuração acontece em $I F_{L}=1,2 \times 10^{-2}$, com a diferença de vértices e arestas em seu valor máximo $\left(\Delta_{V, E}=0,51\right)$.

Para a análise topológica da rede crítica, foi usado o método de Latora e Marchiori (2001). Os resultados das eficiências $\left(E_{\text {global }}=0,25\right.$ e $\left.E_{\text {local }}=0,954\right)$ mostraram que essa rede é mundo pequeno. Considerando o propósito do uso do índice $I F$, a rede crítica encontrada não satisfaz as supracitadas restrições propostas por Watts (1999) e, portanto, não foi aplicado o método de Watts e Strogatz (1998). Além disto, a rede crítica não apresentou nenhuma distribuição de graus característica.

Em relação ao comportamento do caminho mínimo médio $(L)$, à medida que $I F_{L}$ aumenta, a partir de seu menor valor, $L$ vai aumentando uma vez que arestas vão sendo retiradas da rede original. Esse fenômeno, conhecido como "perda de atalhos", continua até chegar na configuração crítica, $I F=I F_{c}$. A partir desse ponto, o caminho mínimo médio cai bruscamente (Figura 6).

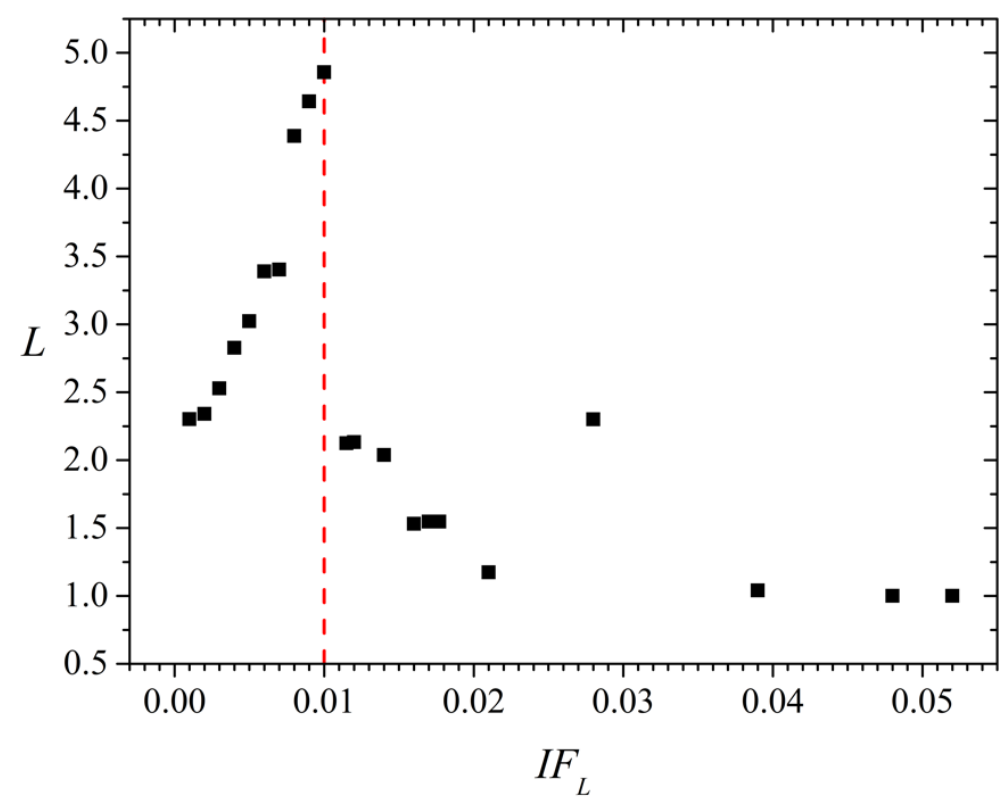

Figura 6. Caminho mínimo médio em função do índice de incidência-fidelidade.

A análise do processo de filtragem também mostra que, à medida que a $I F_{L}$ aumentou, arestas foram sendo eliminadas, e houve a manutenção do mesmo número de vértices, ainda conectados por outras arestas. Por isso, os valores de arestas caíram mais rapidamente que o número de vértices (crescimento de $\Delta_{V, E}$ ) (Figura 7). A Figura 7 mostra que à medida que $I F_{L}$ aumenta, a partir de seu menor valor, a diferenças dos vértices e 
arestas normalizados $\left(\Delta_{V, E}\right)$ também aumenta, ou seja, a perda de arestas é maior que a de vértices. Paralelamente, os caminhos entre os vértices vão aumentando, devido à perda de atalhos. Para valores de $I F_{L}$ próximos à $I F_{c}$ há um alto crescimento de $L$ e um baixo crescimento de $\Delta_{V, E}$.

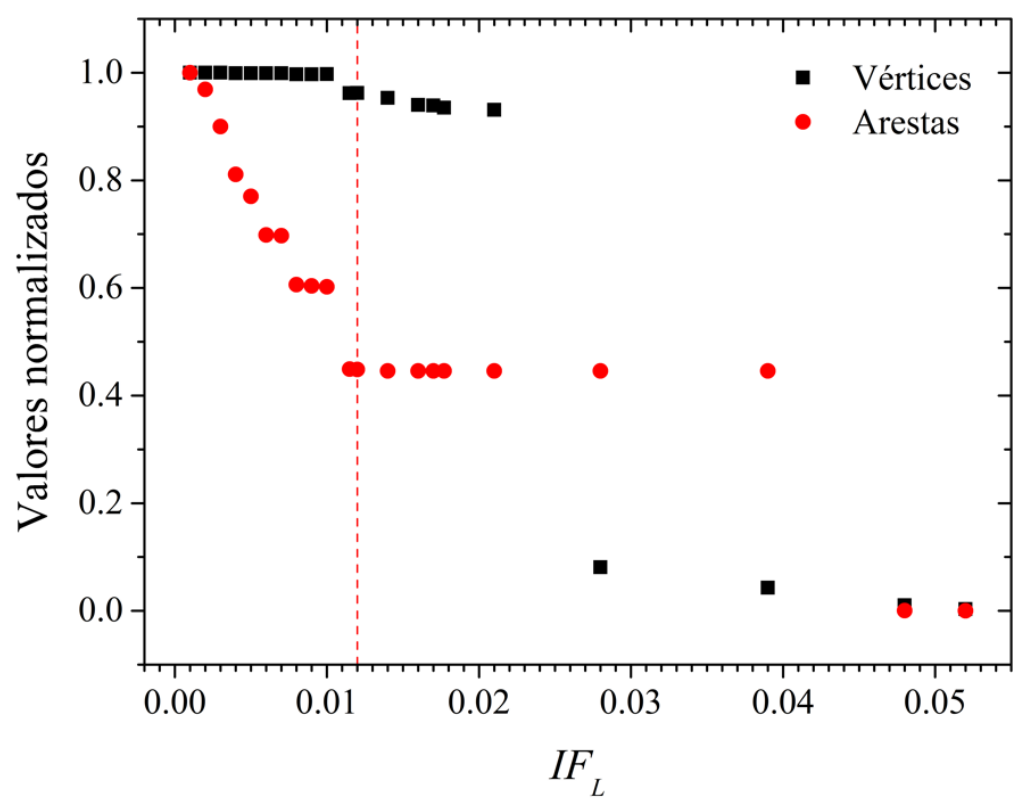

Figura 7. Vértices e arestas normalizados em função do índice de incidênciafidelidade.

Considerando ainda a análise do processo de filtragem, na região circulada na Figura 8, constatou-se que a rede não perde tanta aresta como antes, mantendo aquelas que conectam diferentes comunidades. Após o valor de $I F_{c}=1 \times 10^{-2}, L$ cai bruscamente e o valor de $\Delta_{V, E}$ aumenta bruscamente e a partir daí ele se mantem em uma pequena queda enquanto $L$ continua caindo significativamente (Figura 8 ). Isso mostra que após o valor de $I F_{c}$, as arestas que intermediavam comunidades desaparecem, deixando a rede com diversas comunidades ou cliques isoladas, em uma configuração em que, apesar de alto o valor de $\Delta_{V, E}$, não existe mais uma rede crítica.

O comportamento do coeficiente de aglomeração médio $(C)$ dos vértices, observado na Tabela 5, deve-se ao fato de que à medida que o $I F_{L}$ aumenta, com a diminuição do número de arestas, a rede vai se tornando menos agregada ou, em outras palavras, diminui a tendência dos vizinhos de um vértice serem vizinhos entre si. A partir do valor de $I F_{C}$, a aglomeração aumenta devido à permanência das comunidades até certo valor de $I F_{L}$. 


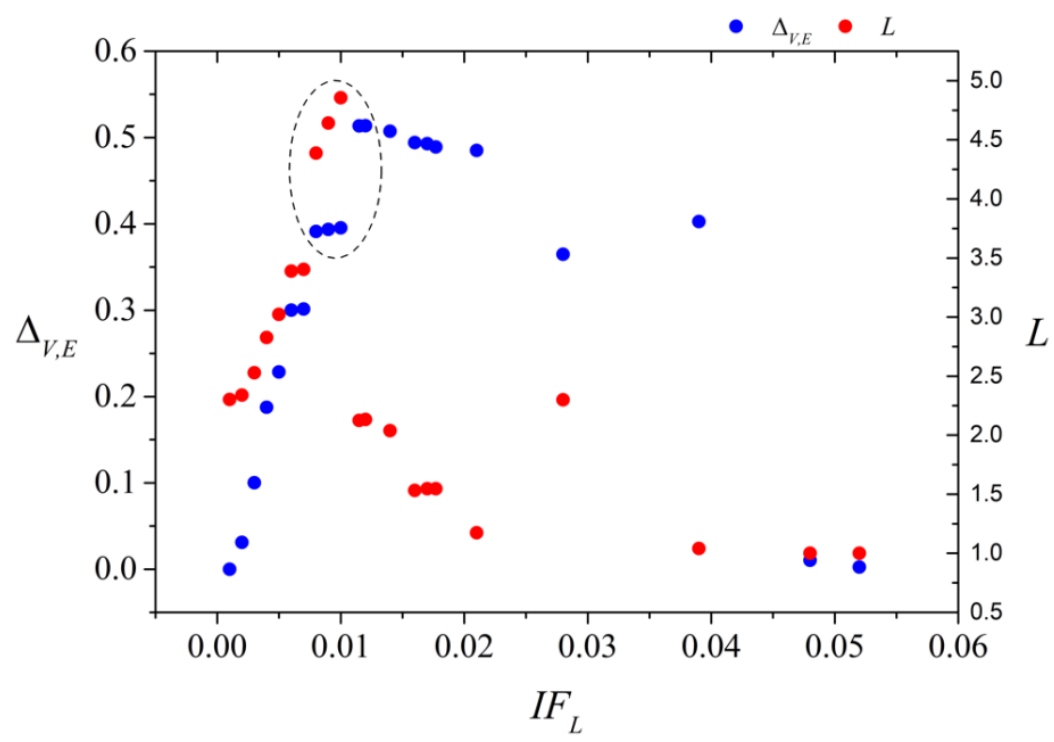

Figura 8. Diferenças dos vértices e arestas normalizados e caminho mínimo médio em função do $I F$.

Em relação ao número de pares não conectados $(P N C)$, na rede crítica (Figura 9) observou-se aumento brusco do número de pares de palavras não conectados de $P N C=$ 5299 quando o $I F=1 \times 10^{-2}$ para $P N C=258890$, quando o $I F=1,2 \times 10^{-2}$. Segundo Teixeira et al. (2010), os pares de palavras formados pelas associações mais fortes são mais relevantes na representação do discurso. Assim, foi realizada a análise da rede crítica para entender melhor o discurso do PPG investigado, iniciando pela análise da importância dos vértices.

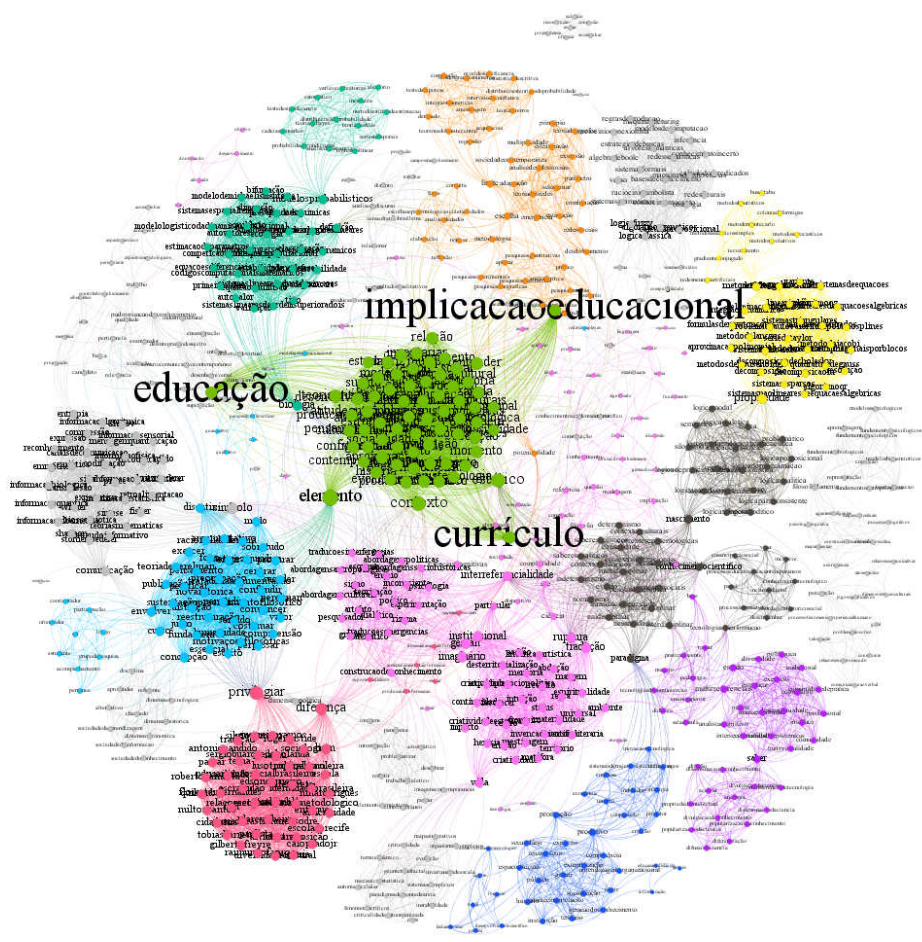

Figura 9. Rede crítica de ementas obtida a partir da aplicação do filtro incidência-fidelidade $I F=0,010$. 
$\mathrm{Na}$ Tabela 5, observa-se que após a retirada dos pares com $I F<1,0 \times 10^{-2}$, houve mudança no posicionamento dos vértices segundo sua centralidade de grau. As 10 palavras da rede de ementas original mais importantes em termo de centralidade de grau, em ordem decrescente, foram: $1^{\circ}$ "conhecimento", $2^{\circ}$ "teoria", $3^{\circ}$ "abordagem", $4^{\circ}$ "difusão do conhecimento", $5^{\circ}$ "sociedade", $6^{\circ}$ "análise", $7^{\circ}$ "processo", $8^{\circ}$ "complexidade", $9^{\circ}$ "pesquisa", $10^{\circ}$ "aplicação". Após a aplicação do filtro, os vértices

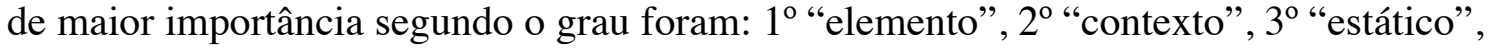
$4^{\circ}$ "privilegiar", 50 "entender", $6^{\circ}$ "teoria critica", $7^{\circ}$ "relação", $8^{\circ}$ "múltiplo", $9^{\circ}$ "configuração", $10^{\circ}$ "conter", $11^{\circ}$ "bases epistemológicas", $12^{\circ}$ "implicação educacional", $13^{\circ}$ "pluralismo cultural", $14^{\circ}$ "educação", $15^{\circ}$ "globalização", $16^{\circ}$ "desenvolvimento social" e $17^{\circ}$ "currículo".

$\mathrm{Na}$ rede original, três temas-chave destacaram-se entre as 10 palavras mais importantes em termos de centralidade de grau, ao quais foram: "conhecimento", "difusão do conhecimento" e "complexidade". Já na rede crítica, essas palavras caíram muito no posicionamento em relação à importância de grau (Tabela 6). Isso pode estar relacionado a essas palavras terem baixa fidelidade com outras palavras nas ementas, com exceção do par "conhecimento" e "difusão do conhecimento".

Assim, observa-se que os temas-chave representativos da área do conhecimento geração e difusão do conhecimento já não aparecem mais entre os termos de maior importância de grau na rede crítica, e palavras relacionadas à área do conhecimento de educação ganham maior destaque-se, e.g. "implicação educacional", "educação" e "currículo", destacados na Figura 9. Isto pode ser um indício de fraca adesão à área de concentração "Modelagem da geração e difusão do conhecimento" e maior aproximação do PPG investigado com a área de educação. Cabe fazer a ressalva de que, por se tratar de uma rede de cliques, o grau sofre influência do tamanho das unidades de significado (i.e. ementas).

Tabela 6: Posicionamento dos vértices/temas-chave em relação à centralidade de grau e aos demais vértices da rede original $(\mathrm{RO})$ e da rede crítica $(\mathrm{RC})$.

\begin{tabular}{|c|l|c|c|c|c|}
\hline TC & \multicolumn{1}{|c|}{ VÉRTICES } & Posição RO & Posição RC & $C G$ RO & $C G$ RC \\
\hline T7 & Conhecimento & 1 & 7 & 277 & 12 \\
\hline T10 & Difusão do conhecimento & 4 & 114 & 240 & 7 \\
\hline T3 & Complexidade & 8 & 28 & 210 & 21 \\
\hline T1 & Método & 12 & - & 190 & - \\
\hline T15 & Modelo & 13 & 41 & 179 & 8 \\
\hline T5 & Ciência & 16 & - & 150 & - \\
\hline T14 & Linguagem & 23 & 286 & 143 & 2 \\
\hline T9 & Cultura & 28 & 268 & 132 & 3 \\
\hline T11 & Epistemologia & 69 & 493 & 89 & 70 \\
\hline T13 & Informação & 129 & 276 & 76 & 1 \\
\hline T8 & Construção do conhecimento & 135 & 109 & 67 & 35 \\
\hline T4 & Comunicação & 145 & 465 & 60 & 46 \\
\hline T6 & Tecnologia & 216 & 142 & 48 & 4 \\
\hline T12 & Geração do conhecimento & 459 & 253 & 29 & 18 \\
\hline T2 & Análise cognitiva & 483 & 591 & 25 & 6 \\
\hline
\end{tabular}


O ponto crítico encontrado neste trabalho $\left(I F_{c}=1 \times 10^{-2}\right)$ é alto em relação a valores encontrados em outros tipos de redes semânticas. Cunha et al. (2015), por exemplo, encontrou valores de $I F$ para redes críticas de título de artigos em periódicos científicos próximos a $10^{-3}$. A partir disto, pode-se inferir que, devido aos pares de palavras terem alta incidência-fidelidade, há uma consistência no vocabulário das ementas, ou seja, muitas palavras se repetem nas ementas e juntas, as quais são vértices que atuam nos processos de justaposição e sobreposição das cliques. Assim, o discurso da proposta de aprendizagem do PPG investigado representado pelo seu ementário apresenta coerência e consistência em relação ao vocabulário.

Analisar um conceito em uma rede semântica é identificar sua posição, importância e significados dentro do contexto do discurso. Assim, para compreender esses conceitos no contexto do discurso do PPG investigado, foram filtradas duas subredes da rede de ementas formadas pelos vértices "difusão do conhecimento" e seus vizinhos diretos (241 vértices e 6799 arestas) e "complexidade" e vizinhos diretos (211 vértices e 7266 arestas). Ressalta-se que essas palavras foram escolhidas por serem temaschave representativos da área de concentração do PPG investigado e por apresentarem grande importância em termos de centralidades.

Na subrede do vértice "difusão do conhecimento" e seus vizinhos (Figura 10 à esquerda), alguns conceitos importantes refletem o que seria a difusão do conhecimento no discurso do PPG investigado: "conhecimento", "teoria", "abordagem", "sociedade", "análise", "processo", "complexidade", "pesquisa", "aplicação", "rede", "método" e "modelo". Essas são as palavras que aparecem mais conectadas à "difusão do conhecimento" segundo a centralidade de grau em ordem decrescente. E aparecem a seguir, destacados em negrito, na discussão do significado de difusão do conhecimento realizada por Ribeiro et al. (2016) que tratam a difusão do conhecimento enquanto processo de veiculação de informações científicas e tecnológicas destinadas à sociedade em geral e a modelagem da difusão do conhecimento, a qual exige teorias e abordagens complexas.

Cinco dos vizinhos com maior centralidade de grau também são palavras que formam pares com maior $I F$, o que reforça a importância desses conceitos na análise do significado de difusão do conhecimento, a saber: "conhecimento", "processo", "teoria", "contexto" e "abordagem". Isso é reforçado pela presença dessas palavras na discursão do significado de difusão do conhecimento realizada por Ribeiro et al. (2016) e comentada no parágrafo anterior. Em relação ao índice $I F$, outras palavras surgem como importantes na conexão com "difusão do conhecimento", como "gestão do conhecimento", "novo", "cultura", "base" e "ciências cognitivas", conceitos que interconectam a difusão do conhecimento com outros conceitos importantes para a descrição da área de concentração e linhas de pesquisa do PPG investigado.

O conceito de "complexidade" (Figura 10 à direita) associa-se às mesmas palavras da subrede de "difusão do conhecimento": "conhecimento", "teoria", "abordagem", "difusão do conhecimento", "sociedade", "análise", "processo", "pesquisa", "aplicação", "rede", "método" e "modelo". Isto ocorre devido à coerência e consistência do vocabulário já discutida anteriormente e pelo fato da palavra "complexidade" estar presente em cinco ementas. 

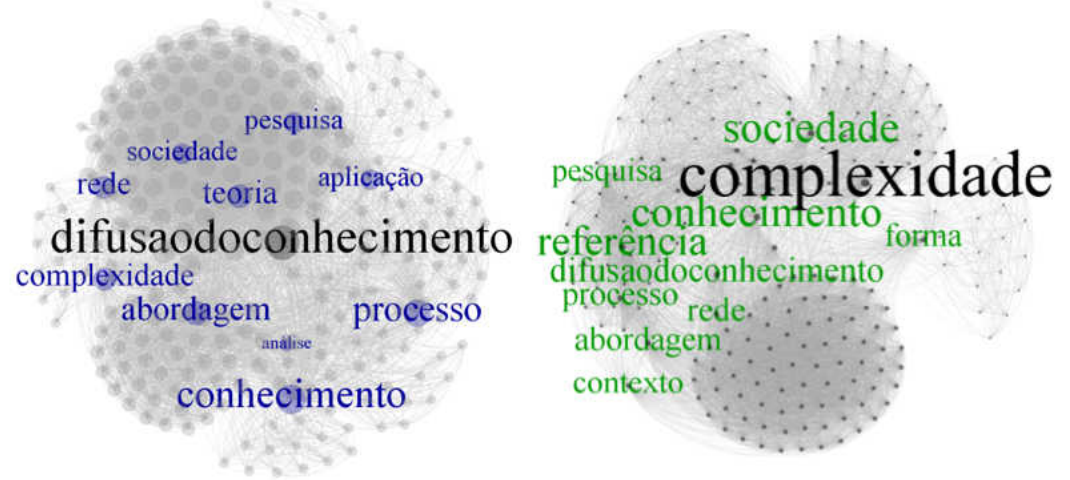

Figura 10. Subredes dos vértices vizinhos aos vértices "difusão do conhecimento" e "complexidade".

A complexidade deve ser compreendida como princípio articulador do pensamento, principalmente se tratando de um PPG da área interdisciplinar. Para o PPG investigado, a compreensão do processo de geração e difusão do conhecimento exige um pensamento pautado nas abordagens do paradigma da complexidade, pois só é possível pensar a difusão do conhecimento de forma integrada à sociedade, à pesquisa e à ciência, conceitos esses que apresentam grande importância na rede de ementas. Para esse alcance, o PPG investigado propõe uma abordagem interdisciplinar e multirreferencial visando a investigação dos processos de geração e difusão do conhecimento pautados na epistemologia da complexidade [Froés Burnham 2016].

Assim, tanto a rede de ementas quanto a rede de componentes curriculares, apresentada a seguir, enquanto redes complexas, podem auxiliar na visão da complexidade do PPG investigado. As abordagens complexas surgem para restabelecer a unidade de diversos fenômenos (natureza, seres humanos, sociedade, entre outros), a qual foi perdida pela divisão compartimentalizada e fragmentada dos saberes oriunda do paradigma tradicional da ciência [Amboni et al., 2012].

O paradigma tradicional da ciência também influenciou a área de educação, onde os currículos dos cursos de graduação ou pós-graduação foram construídos de forma fragmentada e centrados em disciplinas. Os conhecimentos foram segregados em disciplinas compartimentadas e estanques em decorrência do modelo epistemológico racional-positivista. Essa visão de currículo disciplinar dificulta a contextualização, integração e globalização dos saberes [Amboni et al., 2012]. Assim, este trabalho cria e analisa uma rede de componentes curriculares para auxiliar no entendimento das conexões entre os componentes curriculares, e, assim, no entendimento da complexidade do currículo, como será apresentado na próxima seção.

\subsection{Rede de componentes curriculares}

Componentes curriculares são as disciplinas e atividades que compõem a matriz curricular de um curso. Segundo Santomé (2001, p. 55), "Uma disciplina é a maneira de organizar e delimitar um território de trabalho, de concentrar a pesquisa e as experiências dentro de um determinado ângulo de visão". Porém, apenas uma perspectiva não dá conta de investigar objetos complexos, por isso que Santomé (2001) destaca a necessidade de mais integração entre as disciplinas e comenta que no paradigma da complexidade não cabe pensar o ensino compartimentado em disciplinas estanques que não dialogam entre 
si.

Segundo Japiassu e Marcondes (1993), a interdisciplinaridade consiste em um método de pesquisa e/ou de ensino que possibilita que dois ou mais componentes curriculares interajam entre si, seja por meio da comunicação de ideias, integração mútua de conceitos, epistemologias, terminologias, metodologias, procedimentos e dados, ou pela forma de organização de pesquisas.

Com o intuito de perceber a comunicação de ideias e a integração mútua de conceitos, a rede de componente curricular de um PPG teve como objetivo modelar as conexões entre os componentes curriculares por meio de conceitos (i.e. temas-chave) e, desta forma, identificar os componentes curriculares que se relacionam a fim de fornecer subsídios para a promoção da interdisciplinaridade em um curso, conforme discussão a seguir.

$\mathrm{Na}$ rede de componentes curriculares apresentada na Figura 11, o tamanho dos vértices é proporcional ao seu grau. Esse índice indica a quantidade de componentes curriculares adjacentes com que cada um deles se relaciona por meio de temas-chave em comum. O grau também sofre influência do peso das arestas. Neste trabalho, foram atribuídos pesos às arestas, equivalentes à quantidade de temas-chave em comum aos componentes. Os pares de vértices com maior peso são aqueles que possuem mais temaschave em comum. Por exemplo, os vértices "EDCA85 - Epistemologia e Construção do Conhecimento" e "EDCA89 - Processos de Construção do conhecimento" se conectam com peso quatro, uma vez que têm em comum quatro temas-chave: "modelagem", "conhecimento", "complexidade" e "ciência" (Tabela 6).

A rede de componentes curriculares é constituída por 40 vértices e 218 arestas. Possui apenas um componente conectado. É considerada densa $(\Delta=0,279)$ e os componentes curriculares estão conectados em média a aproximadamente outros 11 $(<k>=10,9)$. Isto sugere que os componentes curriculares se relacionam bastante entre si por meio de temas-chave em comum (i.e. há coerência e consistência no currículo).

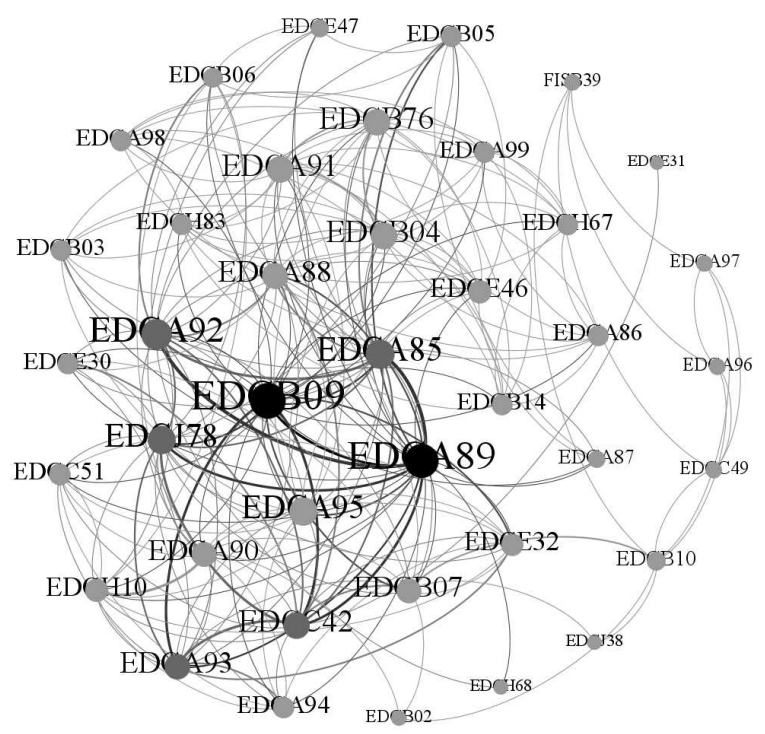

Figura 11. Rede de componentes curriculares do PPG investigado, com destaque para os vértices de maior centralidade de grau. 
No caso da rede investigada, o coeficiente de aglomeração médio é considerado alto $(C=0,815)$, o que indica que os vizinhos dos vértices têm muitos vizinhos entre si, havendo muitas conexões entre os componentes curriculares. Quanto maior o compartilhamento de temas-chave em comum, critério adotado neste trabalho para se estabelecer as arestas, maior a densidade e maior o coeficiente de aglomeração médio, e, assim, maior é a possibilidade de interação entre as disciplinas. $O$ diâmetro da rede investigada é igual a quatro $(D=4)$ e o caminho mínimo médio informa que, em média, a distância entre os componentes curriculares é de 2,11. Essa rede apresenta o fenômeno mundo pequeno identificado pelo método de Latora e Marchiori (2001), cujos resultados das eficiências foram $E_{\text {global }}=0,58$ e $E_{\text {local }}=0,88$.

A apresentação da rede de componentes curriculares e as análises realizadas permitem inferências sobre a multidisciplinaridade do PPG investigado. Segundo Almeida Filho (2005), a partir da classificação proposta por Erich Jantsch em 1972 para alternativas de interação ou integração de distintos campos disciplinares, a multidisciplinaridade é caracterizada pela aposição de várias disciplinas que compartilham um mesmo tema, questão, assunto ou problema em comum. Essa instância de compartilhamento pode ser observada na rede de componentes curriculares estabelecida com base em temas-chave. Neste trabalho, não foi investigada a conexão de disciplinas pelo estabelecimento de relações entre seus docentes ou outra forma de diálogo entre elas. Mas o modelo apresentado pode favorecer com que esses diálogos aconteçam e, assim, surja a interdisciplinaridade auxiliar.

A identificação dos componentes curriculares de maior importância de grau pode contribuir para o estabelecimento da interdisciplinaridade auxiliar no PPG investigado. A interdisciplinaridade auxiliar consiste no relacionamento efetivo entre as disciplinas, havendo coordenação por parte de uma dentre as disciplinas [Almeida Filho 2005], que seriam aquelas com maior importância de grau, ou seja, as que mais interagem com outros componentes curriculares por meio de temas-chave em comum. Assim, supõe-se que os três vértices com as maiores centralidades de grau (i.e. EDCA89, EDCB09 e EDCA92) (Figura 11) sejam os componentes curriculares com maior potencial para a coordenação de projetos de ensino interdisciplinares. Porém, observou-se que um desses componentes curriculares é obrigatório apenas para os docentes da linha um e os outros dois são optativos, o que pode ser condição desfavorável para a implantação de projetos de ensino interdisciplinares nesses componentes, visto que nem todos os discentes do curso irão cursá-los (Tabela 7). Desta forma, além do grau, é importante avaliar outros aspectos, e.g. a natureza do componente curricular, para a implementação de projetos de ensino interdisciplinares nos componentes curriculares.

A centralidade de intermediação expressa o cálculo da fração de caminhos mais curtos entre dois vértices que necessariamente passam por um determinado vértice. Neste trabalho, um vértice que tem uma centralidade de intermediação alta representa um componente curricular que faz a ponte entre outros componentes curriculares. E observou-se que o componente curricular que faz maior intermediação entre os outros é de natureza optativa. Além disso, dos 10 vértices com maiores centralidades de grau, intermediação e proximidade, sete são disciplinas optativas e só três são disciplinas obrigatórias, e um destes é disciplina obrigatória só para os discentes da linha um do PPG investigado (Tabela 7). Assim, as disciplinas optativas possuem maior possibilidade de 
intermediarem os diálogos entre outras disciplinas por meio de temas-chave em comum do que as obrigatórias.

Tabela 7: Medidas de centralidade dos componentes curriculares (CC) e natureza (NAT).

\begin{tabular}{|c|c|c|c|c|}
\hline CC & $C G$ & $C P$ & $C I$ & NAT \\
\hline EDCA89 & 41 & 0,6842 & 0,1046 & OBL 1 \\
\hline EDCB09 & 37 & 0,7091 & 0,2298 & OP \\
\hline EDCA92 & 30 & 0,6393 & 0,0699 & OP \\
\hline EDCA85 & 29 & 0,6190 & 0,0484 & OB \\
\hline EDCC42 & 29 & 0,5909 & 0,0595 & OP \\
\hline EDCJ78 & 26 & 0,6094 & 0,0270 & OP \\
\hline EDCA93 & 23 & 0,5821 & 0,0082 & OP \\
\hline EDCA88 & 19 & 0,5821 & 0,0180 & OB \\
\hline EDCA95 & 19 & 0,5571 & 0,0191 & OP \\
\hline EDCA91 & 18 & 0,5270 & 0,0203 & OP \\
\hline
\end{tabular}

$\mathrm{Na}$ rede de componentes curriculares, foram observadas quatro comunidades (Figura 12). As comunidades agrupam componentes curriculares mais densamente conectados por temas-chave em comum. Segundo Barabási (2016), quanto maior o índice da modularidade $(M)$, melhor será a partição da rede em comunidades. Na rede de componentes curriculares, a modularidade foi igual a 0,323 , o que significa uma partição fraca por ser menor que 0,41. A partir desse valor proposto por Barabási (2016), as partições são consideradas com modularidade máxima ótima. A baixa modularidade encontrada na rede de componentes curriculares pode ser em decorrência de conexões bem distribuídas entre os vértices, ou seja, é difícil distinguir grupos de vértices mais densamente conectados que outros.

A comunidade 4, maior comunidade em relação ao número de vértices (14), é a comunidade que agrupa os componentes curriculares que compartilham o maior número de temas-chave em comum, 13 temas-chave dentre os 15 selecionados para estudo: metodologia, complexidade, conhecimento, cultura, difusão do conhecimento, epistemologia, cognição, ciência, geração do conhecimento, modelagem, comunicação, informação e tecnologia. Sendo assim, os componentes curriculares dessa comunidade podem ser considerados os mais importantes do curso. 


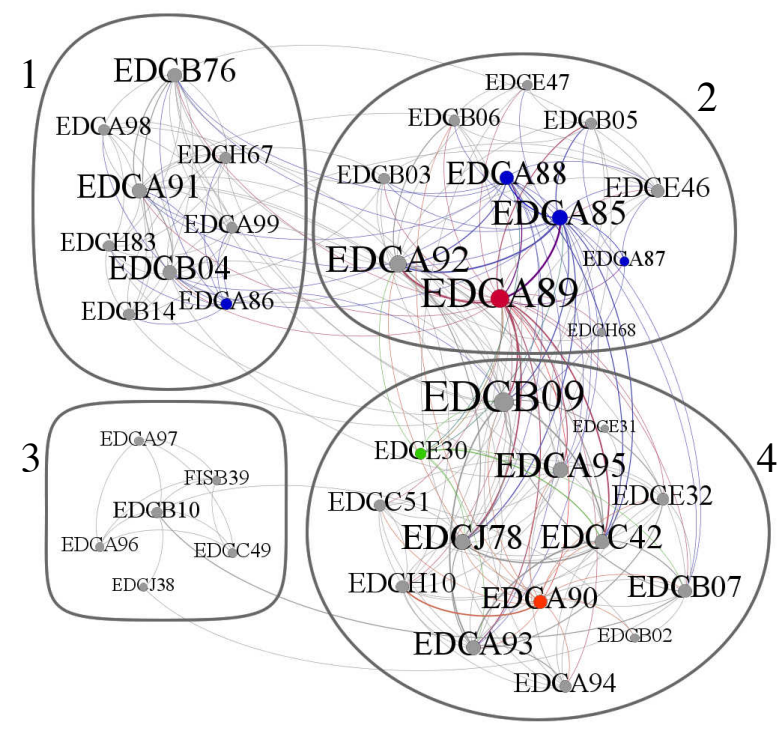

Figura 12. Comunidades da rede de componentes curriculares. Vértices azuis disciplinas obrigatórias. Vértices vermelho, laranja e verde - disciplinas obrigatórias das linhas um, dois e três, respectivamente. Vértices cinzas disciplinas optativas e atividades.

Já a comunidade 3 é formada por nove componentes curriculares que tratam dos temas-chave modelagem, metodologia e linguagem. A linguagem é o único tema-chave que aparece apenas em uma comunidade. Em vista disto, por meio dessa rede, é possível identificar os componentes curriculares que discutem conceitos de interesse. Desta forma, a análise dos temas-chave presentes nas comunidades pode auxiliar na escolha dos discentes pelos componentes curriculares que darão suporte teórico e/ou metodológico aos seus projetos de pesquisa.

\section{Considerações finais}

A rede semântica de cliques baseada em ementas permitiu avaliar a coerência e a consistência entre a proposta de aprendizado baseada nas áreas de concentração e nas linhas de pesquisa de um PPG e o ementário relativo à sua matriz curricular por meio dos índices da análise de redes sociais e índices da teoria das redes complexas.

Neste trabalho, a coerência e a consistência confirmam-se apenas em relação a alguns dos 15 temas-chave. Os vértices "conhecimento" e "difusão do conhecimento" apresentaram os maiores valores de centralidade de grau, proximidade e intermediação, denotando sua importância nas ementas. Essa relevância, porém, não foi observada em relação aos vértices "análise cognitiva" e "geração do conhecimento". Além disso, foi constatado que os processos de justaposição e sobreposição impactam sobremaneira nos índices de densidade, caminho mínimo médio e coeficiente de aglomeração médio da rede de ementas, o que repercutiu em suas características topológicas e na preeminência dos vértices.

A partir da identificação dos temas-chave nas ementas, foi possível agrupar os componentes curriculares por temas-chave e, a partir disto, construiu-se a rede de componentes curriculares. Esse tipo de rede demostra a integração entre os componentes curriculares por meio de conceitos representativos do discurso do PPG investigado, 
segundo sua área de concentração e linhas de pesquisa (i.e. temas-chave). Vale ressaltar que a associação de componentes curriculares pela integração mútua de conceitos é apenas um dos elementos da promoção da interdisciplinaridade. Sugere-se que sejam feitas outras redes de componentes curriculares com outras características de aresta, por exemplo, abordagem epistemológica ou metodologia, e depois se faça a análise interredes.

As redes de ementas e de componentes curriculares sugerem que a teoria de redes pode ser empregada para análise de conexões entre palavras das ementas e entre componentes curriculares da matriz curricular. A análise das conexões entre os conceitos pode auxiliar no melhor entendimento do significado dos conceitos e na identificação de vocabulário relacionado ao objeto de pesquisa dos discentes matriculados em programas de pós-graduação. Já a análise das conexões entre os componentes curriculares pode auxiliar no estabelecimento de critérios de pré-requisitos entre eles e também na identificação de componentes curriculares que sirvam de suporte para o desenvolvimento dos projetos de pesquisa dos discentes.

Desta forma, sendo a teoria de redes uma ferramenta que auxilia no estudo de sistemas compostos por elementos que se conectam e dessas conexões emergem propriedades que vão além da soma das partes, as redes de ementas e de componentes curriculares contribuem para a percepção da complexidade de um PPG. Assim, este trabalho contribui com a elaboração de um modelo computacional baseado na teoria de redes capaz de apoiar o planejamento e avaliação de programas de pós-graduação. Ademais, o modelo pode ser estendido e aplicado para cursos de graduação.

Por fim, destaca-se que, para que o modelo seja capaz de apoiar o planejamento e a avaliação de programas de pós-graduação, é fundamental que membros especialistas do PPG investigado realizem a identificação dos temas-chave e façam as interpretações dos resultados das análises das redes de ementas e de componentes curriculares levando em consideração o projeto do PPG investigado. Em relação a problemas que possam surgir, como por exemplo a identificação inapropriada de temas-chave, é importante considerar qual a causa disso, que nesse caso pode ser, por exemplo, a inexperiência de quem fez a identificação dos temas-chave ou de quem elaborou o currículo. Isso pode ter como consequência a criação de uma rede de componentes curriculares que não represente a real conectividade entre eles. Para resolver tal problema, é mister o estabelecimento de um comitê de especialistas com competências, habilidades e conhecimento do PPG investigado, o que evita a construção de uma rede que não represente a realidade. Assim, recomenda-se que a análise de ameaças à aplicação do modelo proposto considere a identificação da causa, o problema, sua consequência e a resolução proposta.

\section{Referências}

Almeida Filho, N. (2005) Transdisciplinaridade e o Paradigma Pós-Disciplinar na Saúde. Saúde e Sociedade, 14(3):30-50. [GS Search]

Amboni, N., Andrade, R. O. B. de, Lima, A. J. de e Muller, I. R. F. (2012). Interdisciplinaridade e complexidade no curso de graduação em Administração. Cad. EBAPE.BR, 10(2):302-328. doi: 10.1590/S1679-39512012000200005 [GS Search] 
Froés Burnham, T. (2016). DMMDC: uma proposta plural de difusão do conhecimento. In Cognição: aspectos contemporâneos da construção e difusão do conhecimento, $\mathrm{p}$. 19-46. EDUNEB, Salvador, Brasil.

Caldeira, S. M. G. (2005). Caracterização da rede de signos linguísticos: um modelo baseado no aparelho psíquico de Freud. In Mestrado Interdisciplinar em Modelagem Computacional. Fundação Visconde de Cairu, Salvador, Brasil. http://www.cones.ufba.br/producaoGrupo/Dissertacoes/Dissertacao\%20CEPPEVNov2005.pdf

Caldeira, S. M. G., Petit Lobão, T. C., Andrade, R. F. S, Neme, A. e Miranda, J. G. V. (2006). The network of concepts in written texts. The European Physical Journal B Condensed Matter and Complex Systems, 49(4):523-529. doi: 10.1140/epjb/e200600091-3 [GS Search]

Coordenação de Aperfeiçoamento de Pessoal de Nível Superior (CAPES). Diretoria de Avaliação. (2013). Documento de Área 2013. Área de Avaliação: INTERDISCIPLINAR. In Avaliação 2013. http://www.capes.gov.br/images/stories/download/avaliacaotrienal/Docs de area/Int erdisciplinar_doc_area_e comiss\%C3\%A30_ATT27SET.pdf

Cunha, M. V., Miranda, J. G. V. e Pereira, H. B. B. (2015). Incidência Fidelidade aplicada a rede semântica de títulos. In IV Brazilian Workshop on Social Network Analysis and Mining, BraSNAM 2015, XXXV Congresso da Sociedade Brasileira de Computação, CSBC 2015, p. 1-12, Recife. http://www.each.usp.br/digiampietri/BraSNAM/2015/p17.pdf

Erdös, P., Rényi, A. (1960). On the evolution of random graphs. Publications of the Mathematical Institute of the Hungarian Academy of Sciences, 5:17-61. http://snap.stanford.edu/class/cs224w-readings/erdos60random.pdf

Fadigas, I. S. e Pereira, H. B. B. (2013). A network approach based on cliques. Physica A: Statistical Mechanics and its Applications, 392(10):2576-2587. doi: 10.1016/j.physa.2013.01.055

Fadigas, I. S., Henrique, T., Pereira, H. B. B., Senna, V. e Moret, M. (2009). Análise de redes semânticas baseada em títulos de artigos de periódicos científicos: o caso dos periódicos de divulgação em educação matemática. Educação Matemática Pesquisa, 11(1):167-193. [GS Search]

Freeman, L. C. (1978/79). Centrality in Social Networks: Conceptual clarification. Social Networks, 1:215-239. [GS Search]

Grilo, M., Fadigas, I. S., Miranda, J. G. V., Cunha, M. V., Monteiro, R. L. S. e Pereira, H. B. B. (2017). Robustness in semantic networks based on cliques. Physica A: Statistical Mechanics and its Applications, 472:94-102. doi: 10.1016/j.physa.2016.12.087

Gross, J. e Yellen, J. Graph theory and its applications. Boca Raton, CRC Press, 1999.

Henrique, T., Fadigas, I. S., Rosa, M. G. e Pereira, H. B. B. (2014). Mathematics education semantic networks. Soc. Netw. Anal. Min., 4:200. [GS Search]

Japiassu, H. e Marcondes, D. (1993). Dicionário básico de filosofia. Zahar, Rio de Janeiro, Brasil. 
Latora, V.e Marchiori, M. (2001). Efficient behavior of small-world networks. Phys. Rev. Lett., 87:198701. doi: 10.1103/PhysRevLett.87.198701

Lima-Neto, J. L. A., Cunha, M. V. e Pereira, H. B. B. (2018). Redes semânticas de discursos orais de membros de grupos de ajuda mútua. Obra Digital: Journal of Communication And Technology, 14:51-66. doi: 10.25029/od.2017.177.14

Lopes, C. R. S., Cardoso, J. P., Meira, S. S., Casotti, C. A., Vilela, A. B. A. e Pereira, H. B. B. (2015). Significado de corresidência na visão de idosos: uma estratégia para análise cognitiva com uso de redes semânticas. Revista Saúde.com, 11:174-182. http://www.uesb.br/revista/rsc/v11/v11n2a08.pdf

Newman, M. E. J. e Girvan, M. (2004). Finding and evaluating community structure in networks. Phys. Rev. E, 69(2):026113. doi: 10.1103/PhysRevE.69.026113

Nussensveig, H. M. (2008). Complexidade e Caos, Coordenação de Programas de Estudos Avançados (COPEA), UFRJ, Rio de Janeiro, Brasil.

Paumier, S. (2008). UNITEX 2.0. User Manual, Université Paris-Est Marne-la-Vallée. http://unitexgramlab.org/releases/2.0/man/Unitex-GramLab-2.0-usermanual-en.pdf

Pereira, H. B. B., Fadigas, I., Senna, V. e Moret, M. (2011). Semantic networks based on titles of scientific papers. Physica A: Statistical Mechanics and its Applications, 390(6):1192-1197. doi: 10.1016/j.physa.2010.12.001

Pereira, H. B. B., Fadigas, I. S., Monteiro, R. L. S., Cordeiro, A. J. A. e Moret, M. A. (2016). Density: A measure of the diversity of concepts addressed in semantic networks. Physica A: Statistical Mechanics and its Applications, 441:81-84. doi: 10.1016/j.physa.2015.08.024

Ribeiro, N. M., Menezes, A. M. F., Campos, M. de F. H. (2016). Difusão e gestão do conhecimento: conceitos, analogias, divergência e convergências. In Cognição: aspectos contemporâneos da construção e difusão do conhecimento, p. 151-194. EDUNEB, Salvador, Brasil.

Rosa, M. G. (2016). Modelo empírico para analisar a robustez de redes semânticas. In Doutorado Multidisciplinar e Multi-institucional em Difusão do Conhecimento. Universidade Federal da Bahia, Salvador, Brasil.

Santomé, J. T. (2001). Globalização e interdisciplinaridade - o currículo integrado. Vozes, Petrópolis, Rio de Janeiro, Brasil.

Solomonoff, R., Rapoport, A. (1951). Connectivity of Random Nets. Bulletin of Mathematical Biophysics, 13:107-117. [GS Search]

Teixeira, G., Aguiar, M., Pereira, H., Miranda, J., Cunha, M., Morais, J., Carvalho, C. e Dantas, D. (2010). Complex Semantic Networks. International Journal of Modern Physics C, 21(3):333-347. doi: 10.1142/S0129183110015142

Watts, D. J. (1999). Small Worlds: The dynamics of Networks between Order and Randomness. Princetown University Press, New Jersey.

Watts, D. J. e Strogatz, S. H. (1998). Collective dynamics of small-world networks. Nature, 393(4):440-442. [GS Search] 